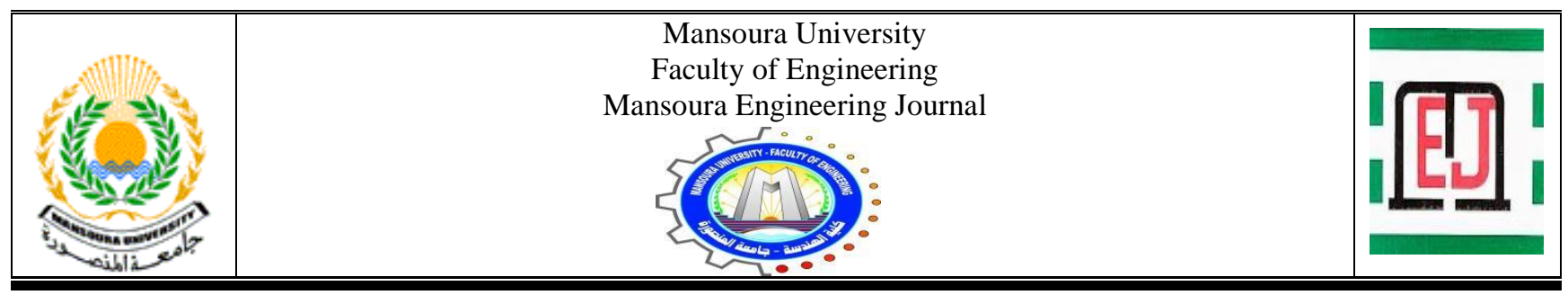

\title{
An Analytical Study for The Reflection of the Design and Co-Ordination of Urban Spaces to Improve Their Functional, Environmental and Aesthetic Performance
}

\author{
Reda Mahmoud Hamada Aly and Heba Mohamed Ahmed Abdou
}

\begin{tabular}{|l|}
\hline KEYWORDS: \\
Urban spaces, \\
physical components, \\
functional performance, \\
environmental \\
performance, \\
aesthetic performance. \\
\\
\hline
\end{tabular}

Abstract - The elements of space design and coordination are the most
important elements of attraction that give urban space a kind of excitement and
distinction. Due to the neglect of urban spaces, the elements of designing and
coordinating lost their importance in these spaces. Hence, the research problem
is the lack of a clear conception of the role of elements of designing and
coordinating of urban spaces to improve their functional and environmental
performance and enrich their aesthetic aspects which led to the unwillingness of
the city's residents to exploit these spaces. Therefore, the research aims to clarify
the relationship between the elements of designing and coordinating the urban
spaces and their functional, environmental, and aesthetic performance and
improving the efficiency of the urban spaces, in order to be prepared to serve
individuals and communities and to be a mirror that reflects the image of the
city. Therefore, the research relied on the analytical approach through studying
the theoretical framework of the research problem, based on studying and
highlighting the importance, components, properties and classification of these
spaces. Also, it relied studying the design systems of urban spaces and the
contributed elements which improve functional, environmental and aesthetic
performance, in addition to conducting a comparative analysis between the
study cases, to measure the extent of applying what has been reached in the
theoretical study in the study cases. Finally, it has been evident that there is no
design of urban spaces based on engineering basis that follow the standards
discussed in the research, and it lacks of the minimum and necessary physical
components.

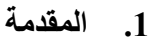

|ختلف مفهوم الفراغات الحضرية على مر العصور بسبب اختلاف

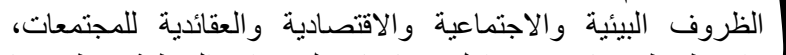

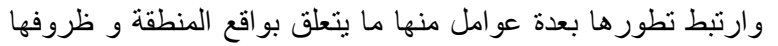

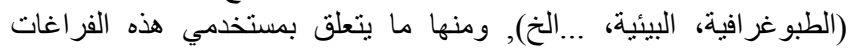

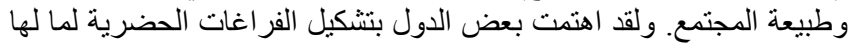

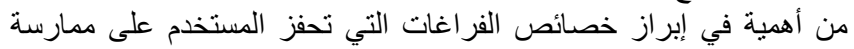

الأنشطة المختلفة, ولكن في مصر فالتغير التهات التي حدثت في نهاية الألفية الثانية

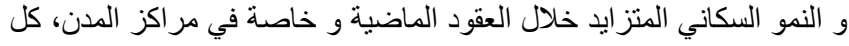

Received: (2December, 2020) - Revised: (17 February, 2021) Accepted: (17 February, 2021)

Assoc. Prof. Reda Mahmoud Hamada Aly, Associate Professor, Dept. of Architectural Engineering Faculty of Engineering, Al Azhar university (redda.ali70@azhar.edu.eg,youssef1732018@gmail.com)

Corresponding Author : Dr. Heba Mohamed Ahmed Abdou, Lecturer, Dept. of Architectural Engineering, Faculty of Engineering, Mansoura University (arch heba84@mans.edu.eg, arch heba84@yahoo.com ) 
عدم وجود تصور و اضح لدور و أهمية عناصر تصميح وتنسيق الفراغ اغناتئ

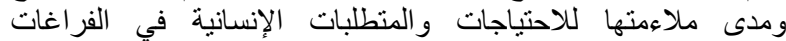

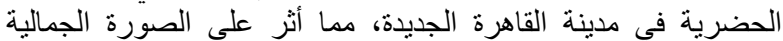
و الأداء الوظيفي و البيئي لهذه الفر اغات.

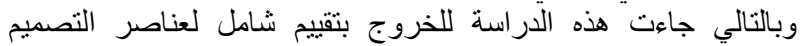

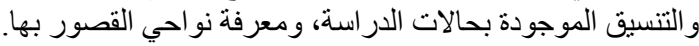

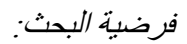

يفترض البحث أن القصور في تصميم الفراغات الحضرية وافتقارها لعناصر تنسيق الموقع للفر اغات الحضرية يؤدي إلى خلى خلل كبير في في الأداء

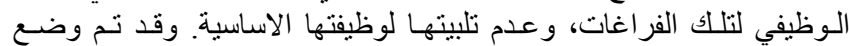

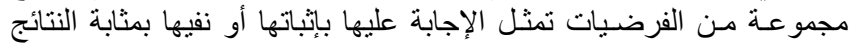

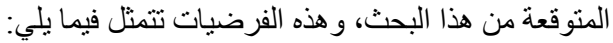

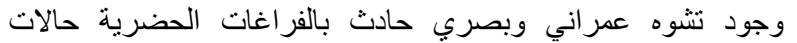
الار اسة.

التأثير السلبي على احتباجات ومتطلبات الأفراد (وبالتالي على الأداء

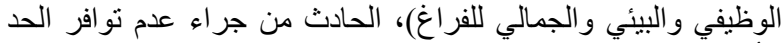

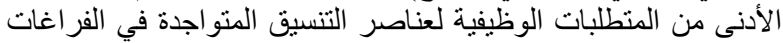

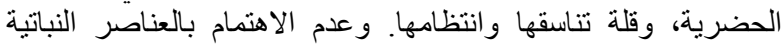

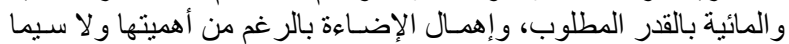

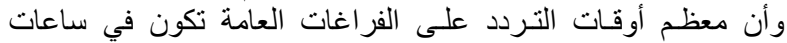
المساء.

تصميم وتتسيق الفراغات الحضرية يعمل علي تحسين الأداء الجمالي و الوظيفي و البيئي ويعمل علي تحسين كفاءة الفر اغات الحضرية.

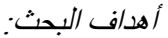

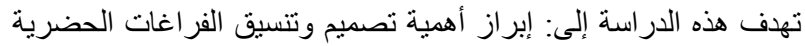

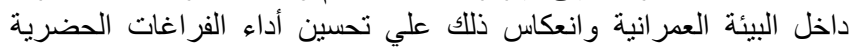
الوظيفية والبيئية و الجمالية.

ذللك أدي إلى انحصار دور الفراغات الحضرية في إثراء المعايشة الإنسانية

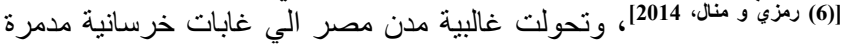

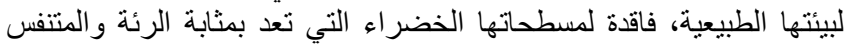

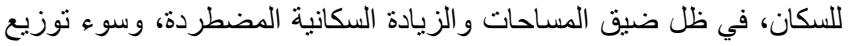

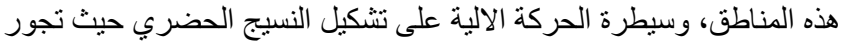

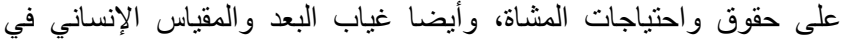

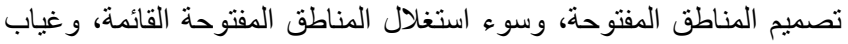

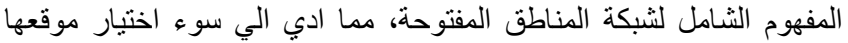

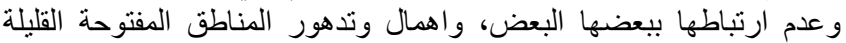

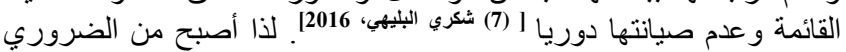

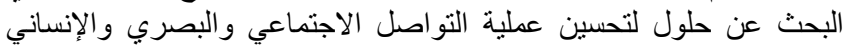

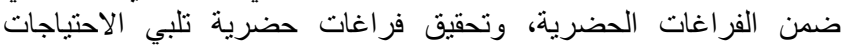
و المتطلبات الإنسانية من خلال تصميمها وتتسيقها.

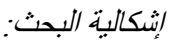

تتمثل الإشكالية البحثية في فقدان الفراغ الحضري (بمصر بصفة عامة

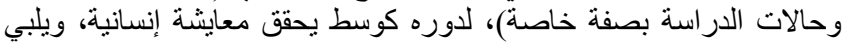

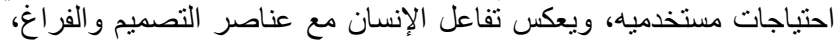

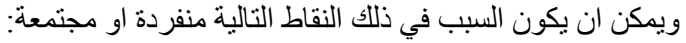

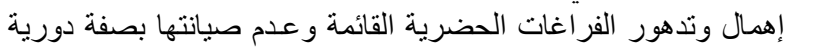
و الحفاظ عليها.

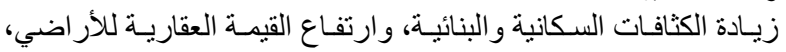

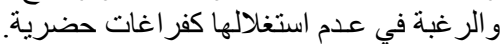

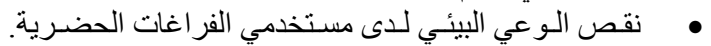

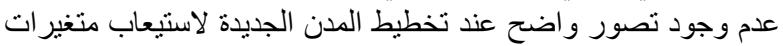
ما بعد الإشغال بسب التطور اتص ات المتلاحقة للكثافة السكنية.

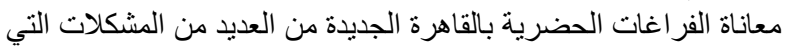

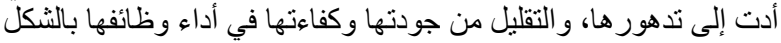

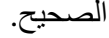

افتقار الفراغات الحضرية لوجود عناصر تصميم وتنسيق الفراغ وقلة ولة وإنة

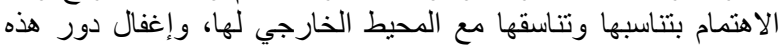

العناصر و أهميتها الجمالية و الوظيفية ولنية والبيئية.

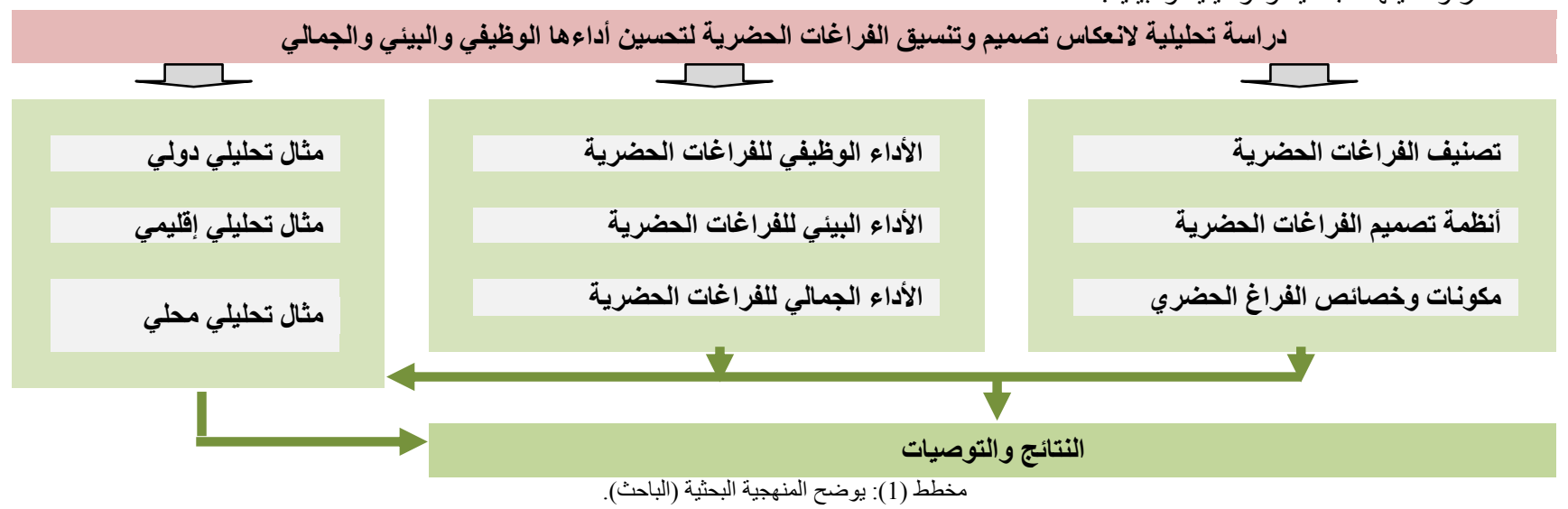

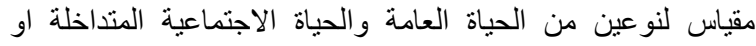

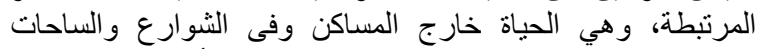
و الحدائق الكبيرة و الفر اغات الاجتماعية وساحات العات الأسواق.

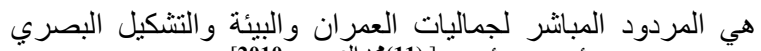
و إنطباعاتها في أذهان الأفر اد [ (11)محئ العيسوي، 2010].

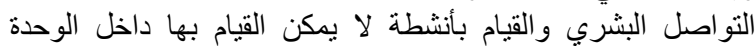

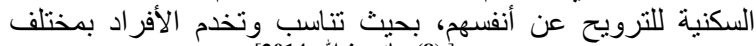

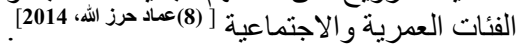

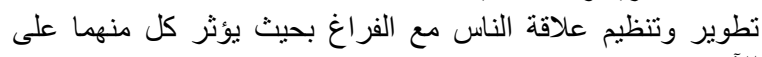
الآخر. توفر الراحة و الهدوء النفسي لمستخدمي الفراغ.

\section{2. - أهمية الفراغات الحضرية.}

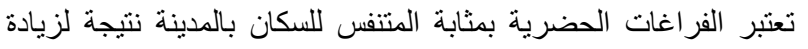

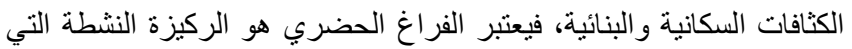

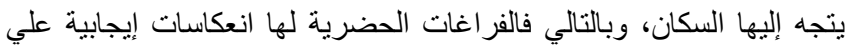

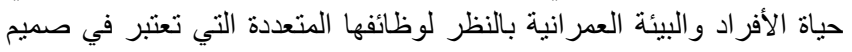

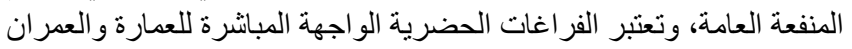

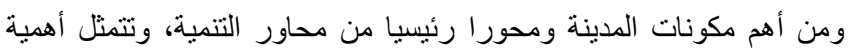
الفر اغات الحضرية في النقاط التالية: 
• تعمل على رفع زوق المو اطنين وثقافتهم البيئية و الاجتماعية. كما تضفي

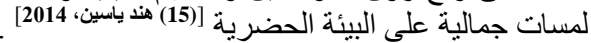

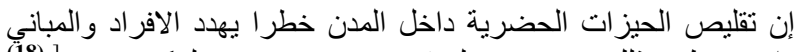

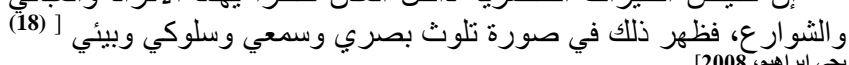

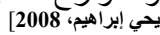

\section{3.}

الهدف الأساسي من تصنيف الفراغات الحضرية الوقوف على أنواعها

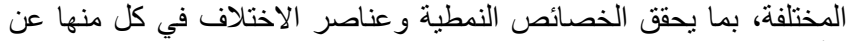

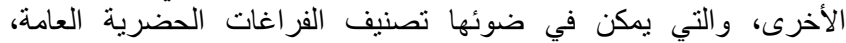

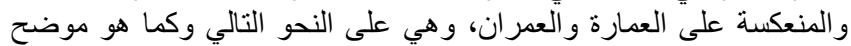

بمخطط (2):
تؤثر البيئة الفيزيائية المتوفرة في الفراغ الحضري على سلوك

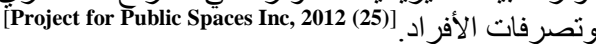

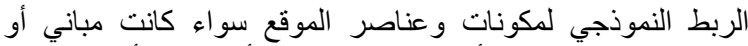

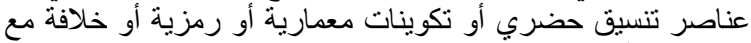

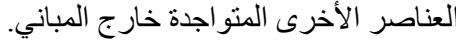
عنصرا هاما في تشكيل المدينة وحلقة الوصل الوحل بين العمارة الداخلية و والخارجية ربط الفراغ والمجتمع، حيث يصعب وجود فراغ من غير إغ محتوى

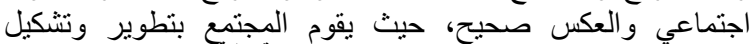
الفر اغات بمختلف الوسائل و الطرقئ [ (4)جورج قتصلية، 2013] تحفيز العلاقات الجوارية والحميمية بين السكان والطين مما يقوي شعور هم بالانتماء و الألفة لمناطق إقات القانهم.

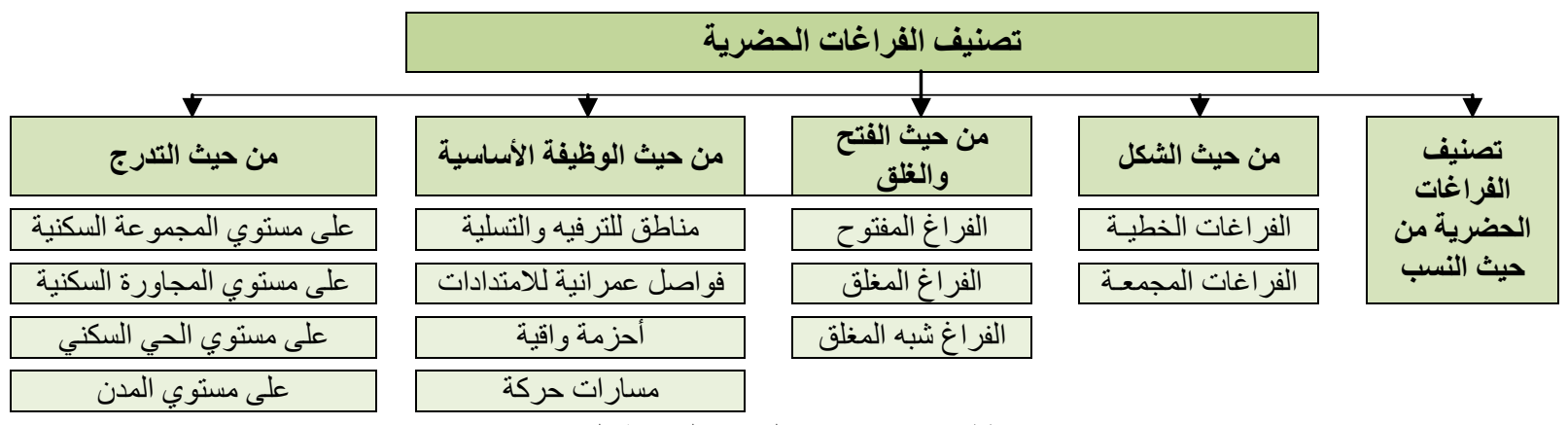

مخطط (2): يوضح تصنيف الفر اغات الحضرية (الباحث)

$$
\text { 1-2-3 الفراغات الخطية (الديناميكي) }
$$

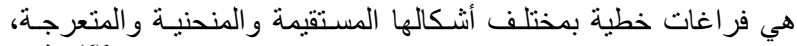

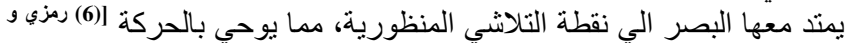

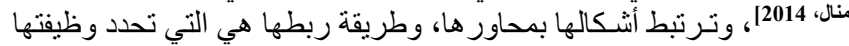

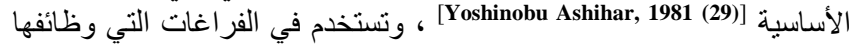

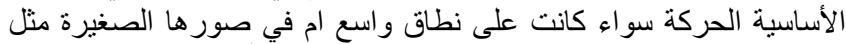

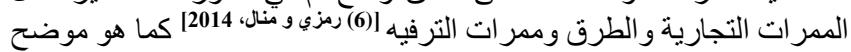

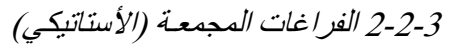

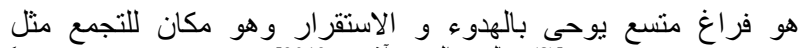

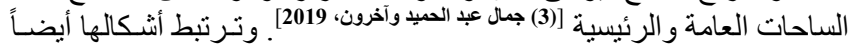

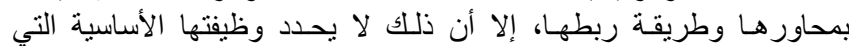

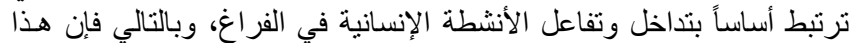

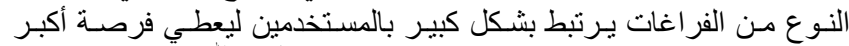

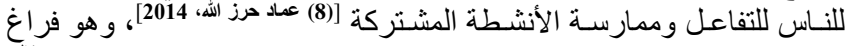

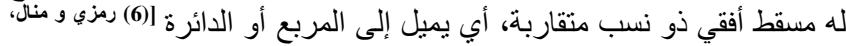

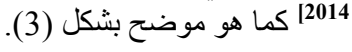

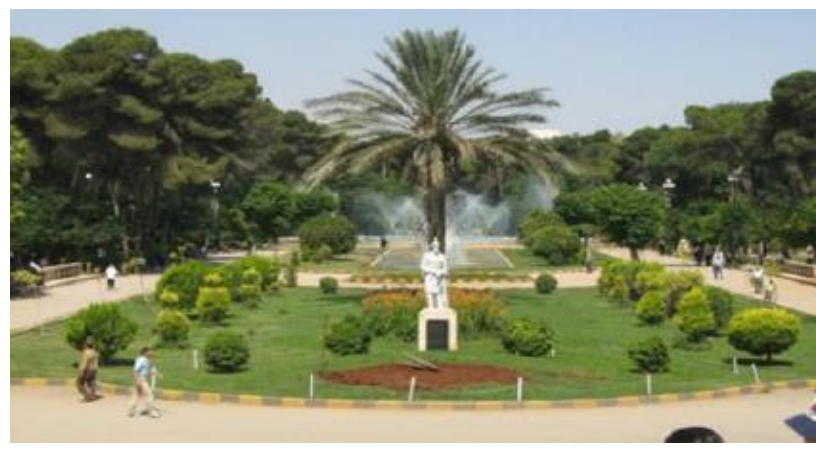

وآخرون، (3)): يوضح فراغ استاتيكي يوحي بالاستقرار" حديقة عامة بدبي" [(3) جمل عبد الحميا
1-3 تصنيف الفراغات الحضرية من حبث النسب

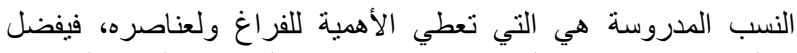

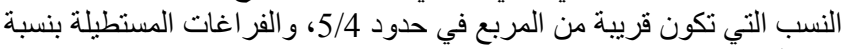

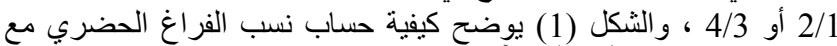
ارتفاع المبني. [ (3) جمال عبد الحميد وآخرون، 2019 أحيفة

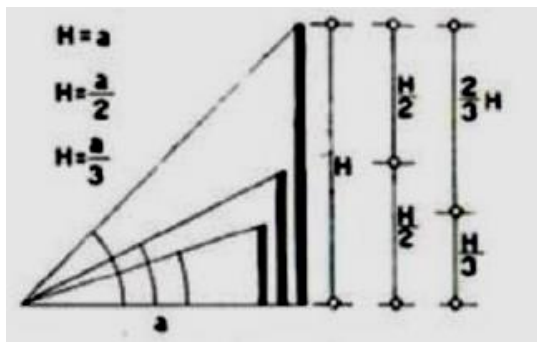

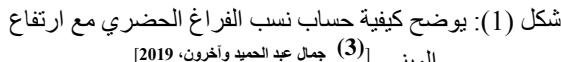

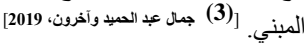
3-3 تصنبف الفراغات الحضرية من حبث الثكل

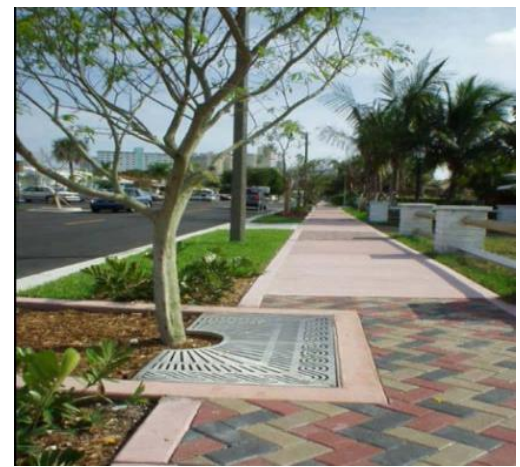

شكل (2):) يوضح فراغ خطي ديناميكي "ممر مشاة" [2017Muhammad Amer 


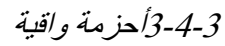

تستخدم المناطق المفتوحة للتحكم في الظروف المحية المبطة بمنطقة التنمية أو

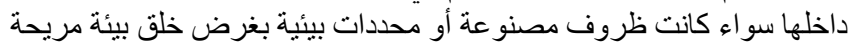

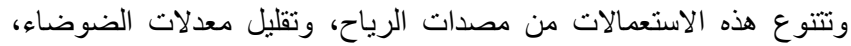

وتقليل معدلات تآكل التربة (التصحر ).

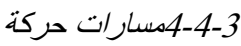

مناطق مفتوحة للطرق: ويختلف شكل ومساحة وتكوين هذه الهناطق تبعا

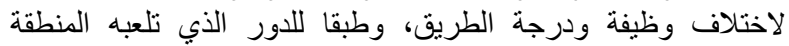

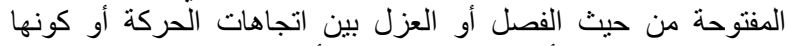

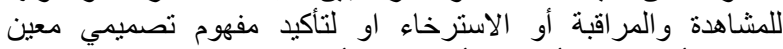

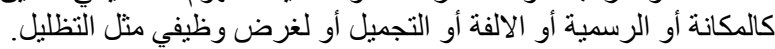

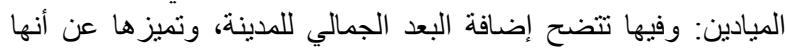

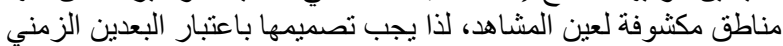

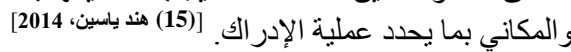

\section{5-3 تصنيف الفراغات الحضرية من حيث التلدرج}

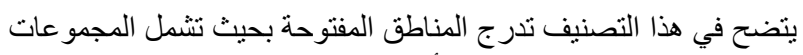
السكنية، والمناطق المفتوحة للمدن و الأقاليم.

1-5-3 على مستوي الدجموعة السكنية

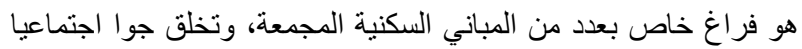

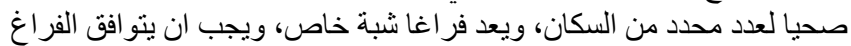

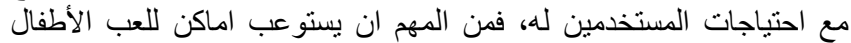

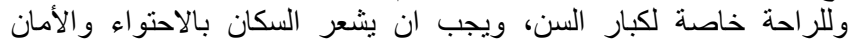

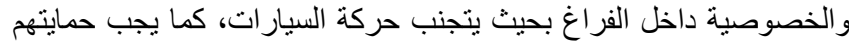

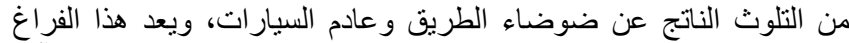

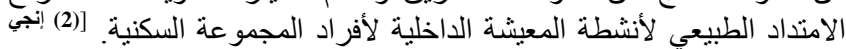

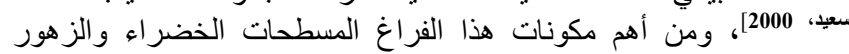

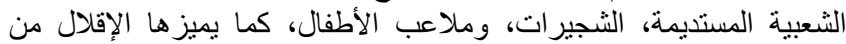

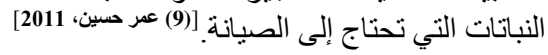

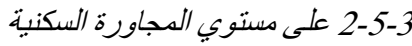

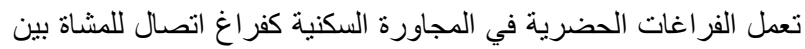

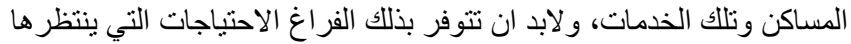

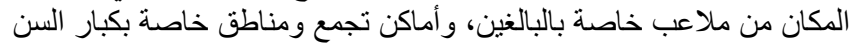

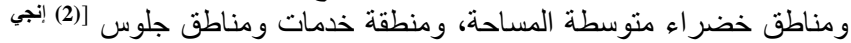

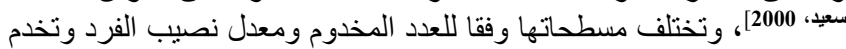
الفر اغات الحضرية سكان المجاورة على مختلف أعمار هم. [(9) عر حسين، 2011]

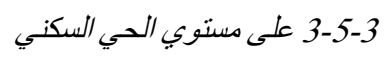

ويتأثر بالخصائص الطبيعية للمكان وله دور كبير في توفير اتصال مبانر الهنر

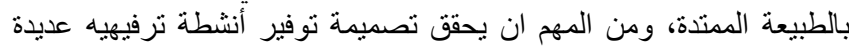

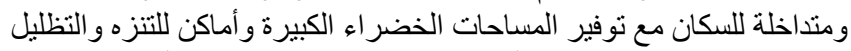

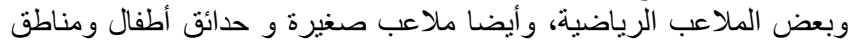

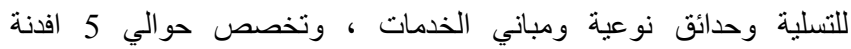

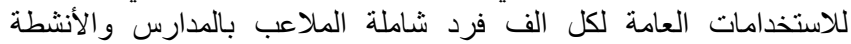

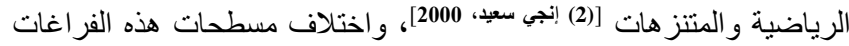

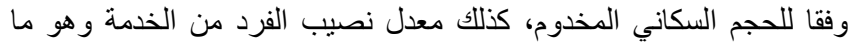
يختلف وفقا لمنطلبات وطبيعة التتمية. [(9) عد حسين، 2011]

$$
\text { 4-5-3 على مستوي الدينة }
$$

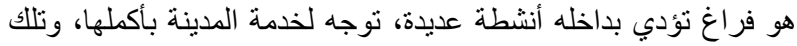

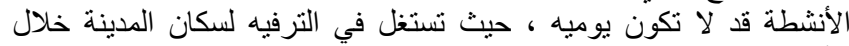

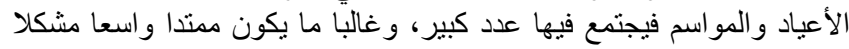

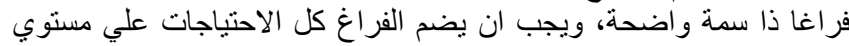

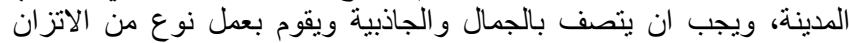
الايكولوجي للمدينة ، ويحدد هذا الفراغ بحدود طبيعية مثل الجبال او الأشجار

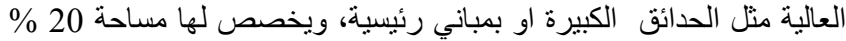

3-3تصنيف الفراغات الحضرية من حيث الفتح والغلق

تصنف تلك الفراغات الحضرية من حيث علثرات علاقتها بالكتل المحيطة ومسار ات الحركة كالتالى، ويوضح شكل (4) أنثكال تلك الفر اغات: 1-3-3 الفراغ الدفتوح

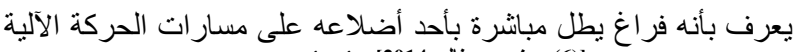

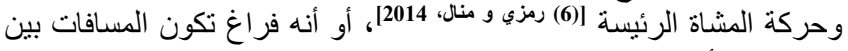

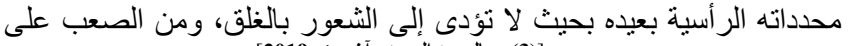
الإنسان إدر اكه في الطبيعة. [(3) جمال عبد الحميد وآخرون، 2019]

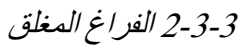

هو الفر اغ المحاط بالمباني (محدد الجوانب) من جميع الجهات وينفصل

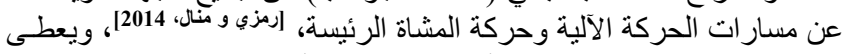

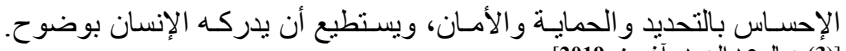

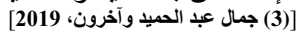

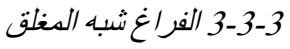

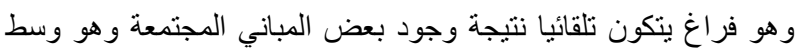

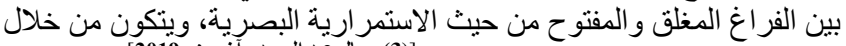
العلاقة بين المباني و العناصر الطبيعية. [(3) جمال عبد الحفيد وأزرون، 2019]

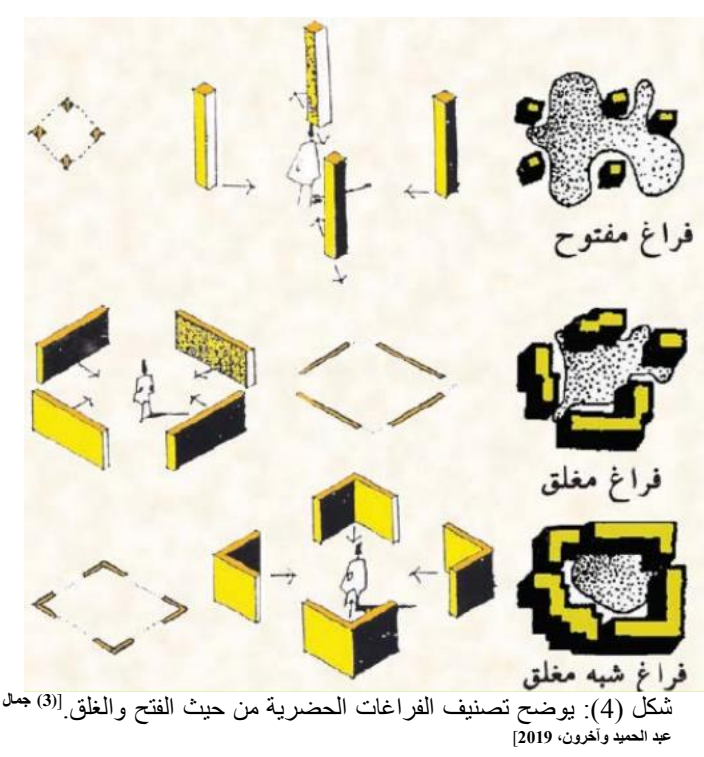

4-3 تصنيف الفراغات الحضرية من حيث الوظيفة الأساسية (النشاط)

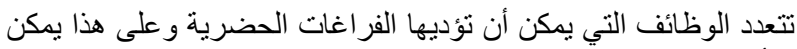
أن تعد أساس للتصنيف كما يلي: 1-4-3 مناطق للترفيه والتسلية كنائي

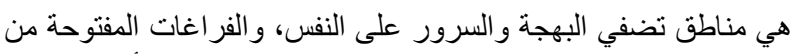

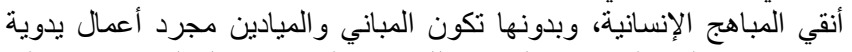

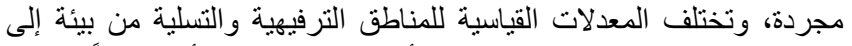

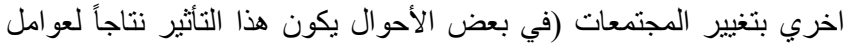

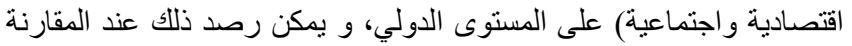

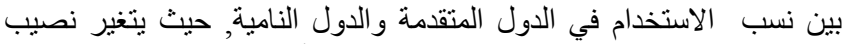

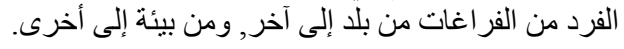

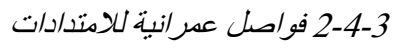

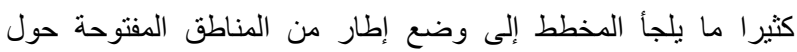

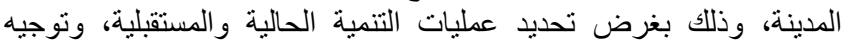

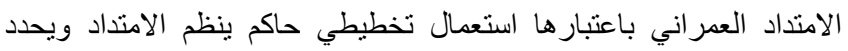
عمليات التنمية، كذلك تعتبر متنفس عام لسكان الدينة. 


$$
\text { 3-4 النسق المختلط أو المشترك المن المن }
$$

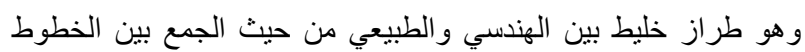

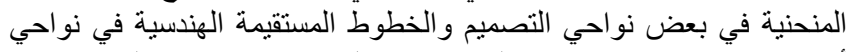

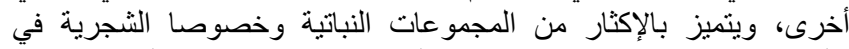

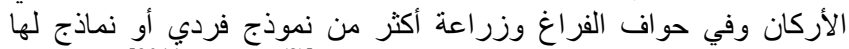

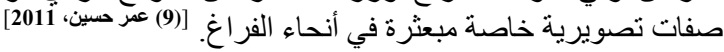

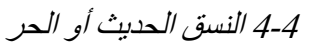

يطلق عليه النسق الأوروبي أو طراز أمريكا الثمالية وأساسه البساطة

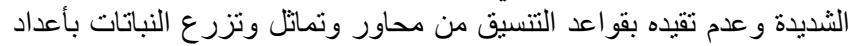

ققليلة، ولكن اختيار ها كنماذج فردية ولها صنفات تصويرية خاصنة.

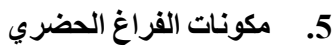

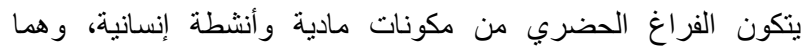

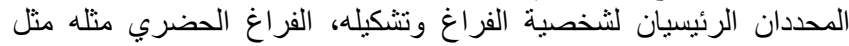

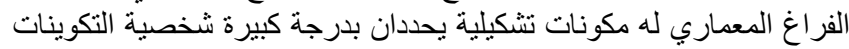

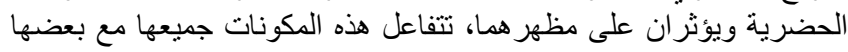

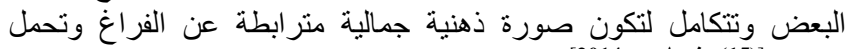

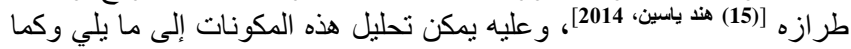

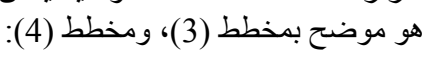

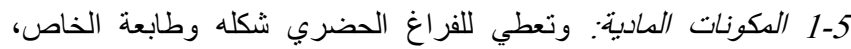

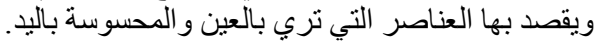
2-5 الأنشطة الإنسانية: وهي كل ما يتعلق به من أنشطة وسلوك وتصرفات النّات

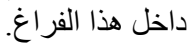

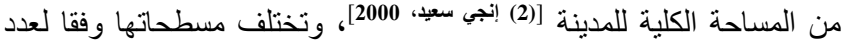
سكان المدينة، كذلك وفقا لمعدل نصيب الفرد من هذه الفراغات. [(9) عمر حسين، [2011

\section{4. أنظمة تصميم الفراغات الحضرية}

بمكن حصر طرق تصميم وتخطيط الفراغات الحضرية داخل إطار من أربعة

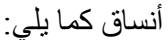

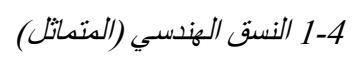

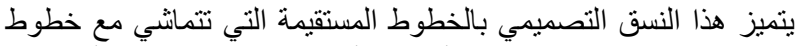

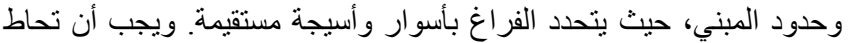

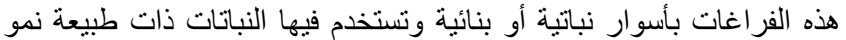

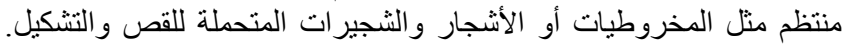

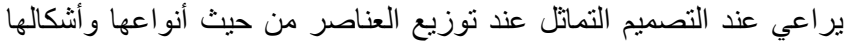

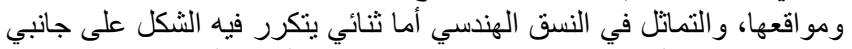

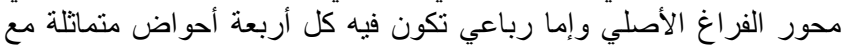

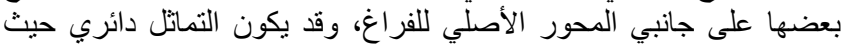
تتكرر فيه الأجزاء بشكل دائري أو بيضاوي حول حوض وسط دائري أو الو دائري بيضاوي.

2-4 النسق الطبيعي باري

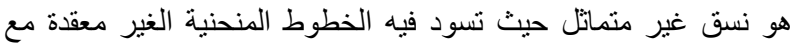

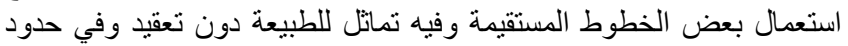

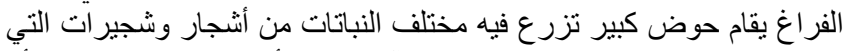

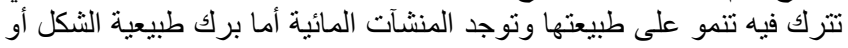
ممر ات مائية.

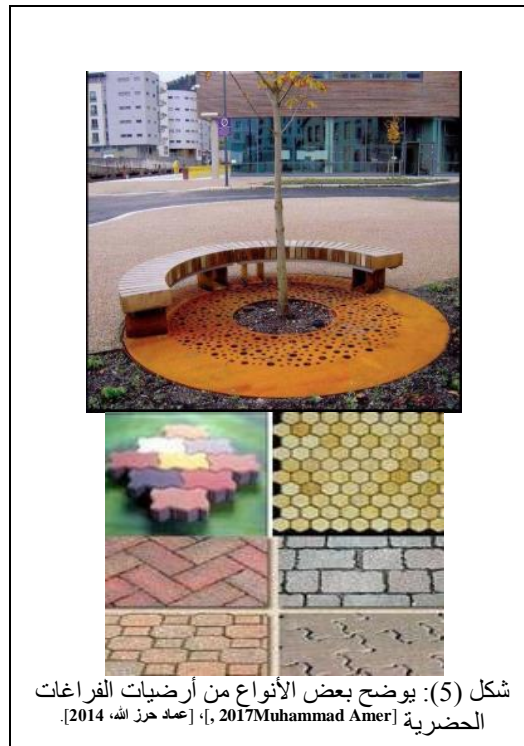

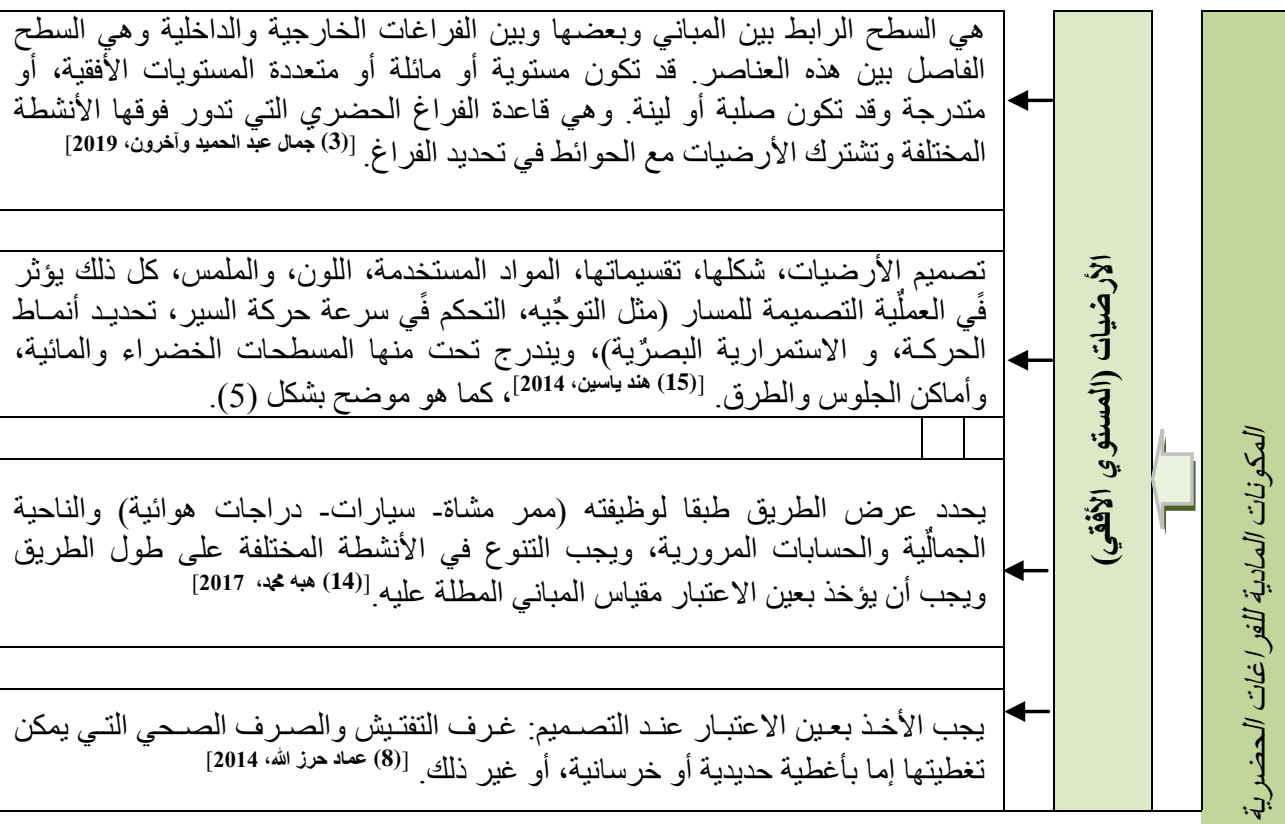

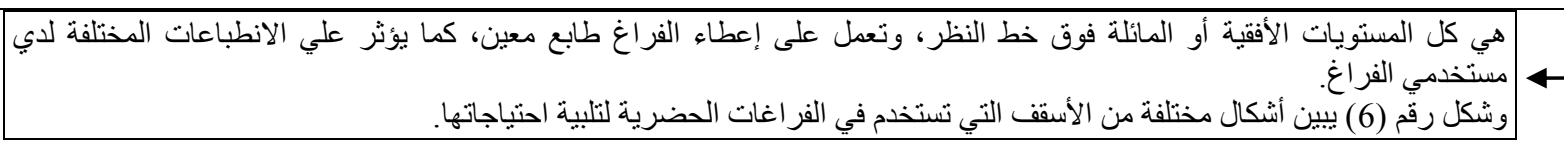

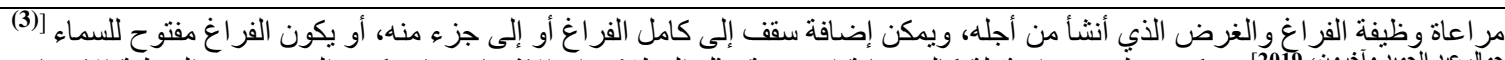

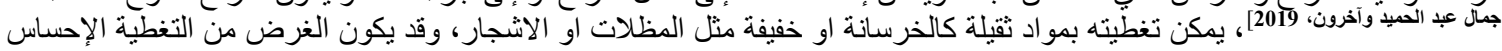

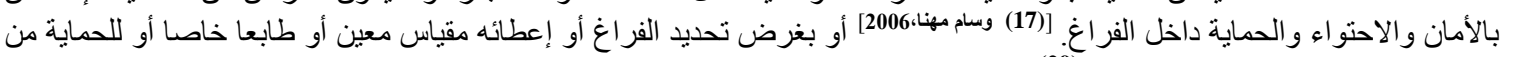




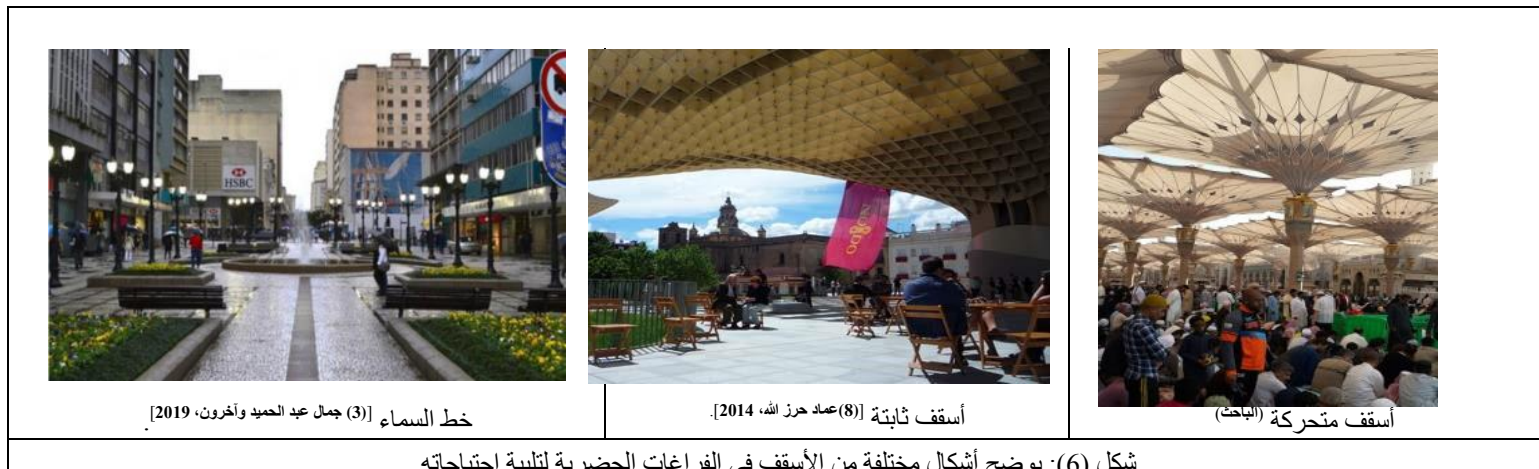

شكل (6): يوضح أشكال مختلفة من الأسقف في الفر اغات الحضرية لتلبية احتياجاته.

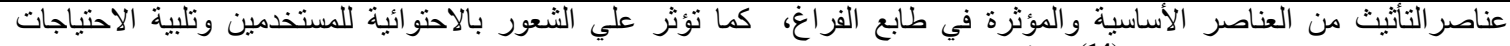

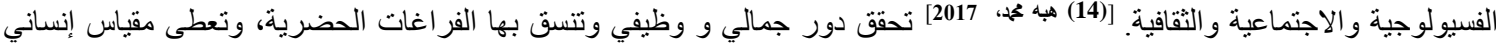

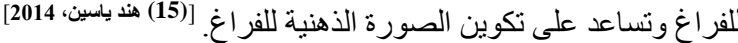

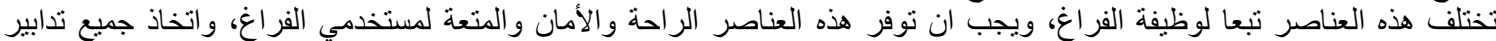
السلامة. يجب أن يجسد الأثاث الحضري مبادئ التصميم منل "البساطة و التناغم، التناسب واهن والأيقاع، التكوين، و الرمزية. [(17) وسام مهنا،2006]

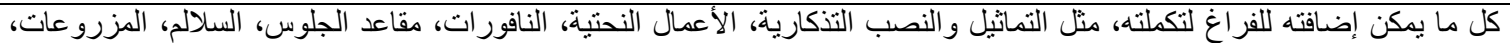

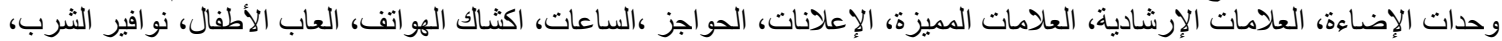

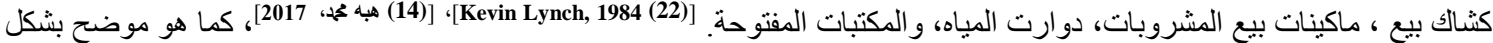
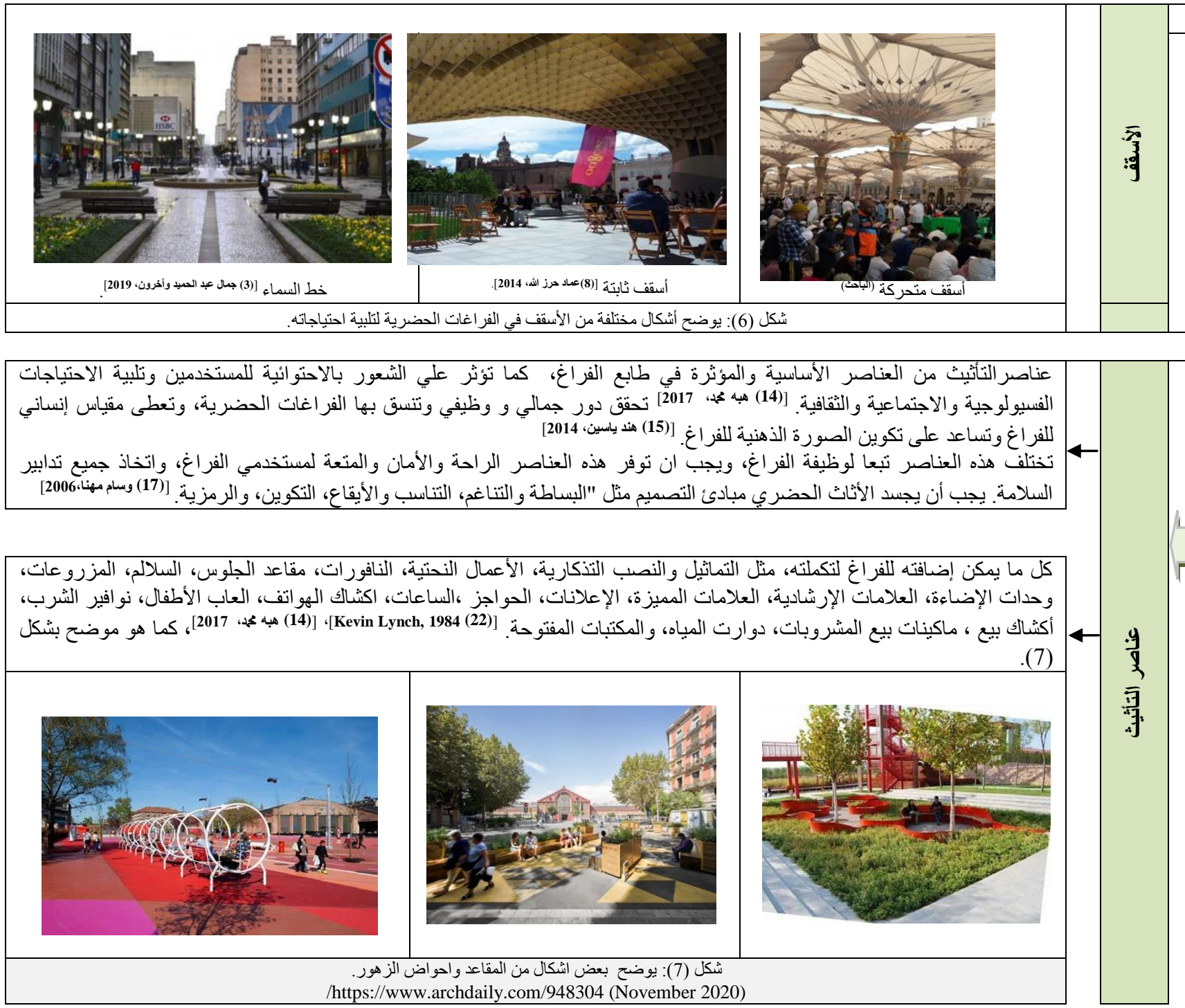

https://www.archdaily.com/948304 (November 2020)

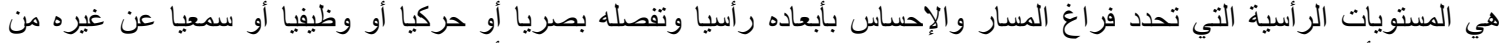

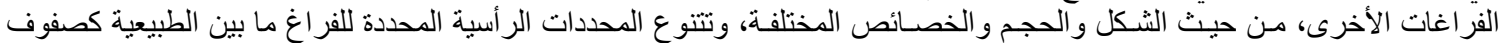

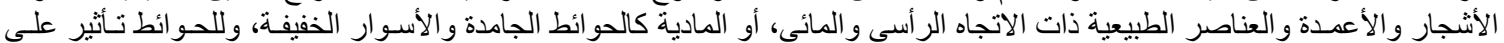

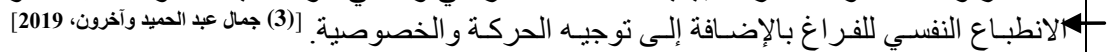

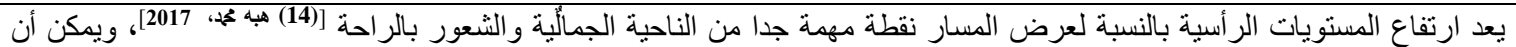

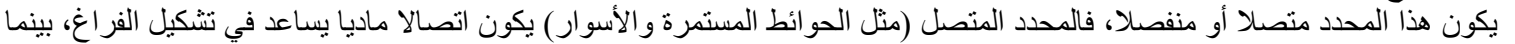

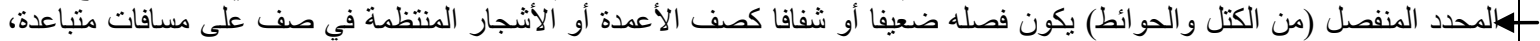

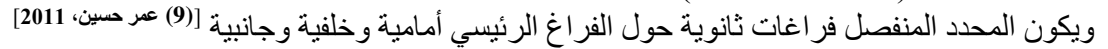

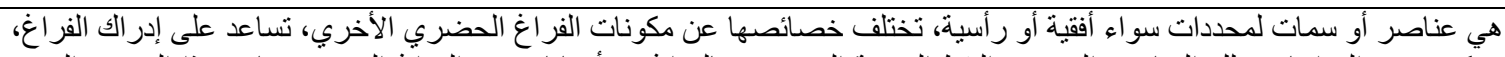

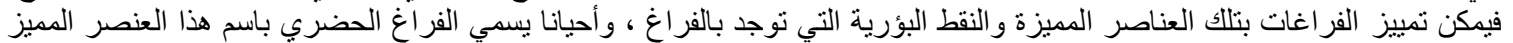

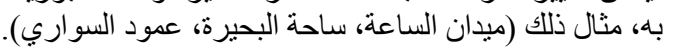

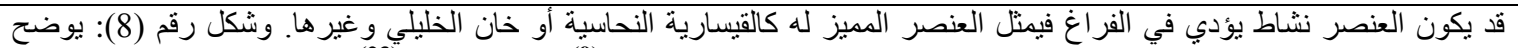
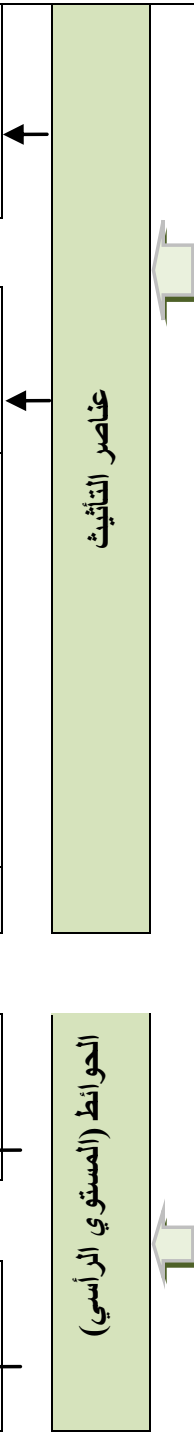

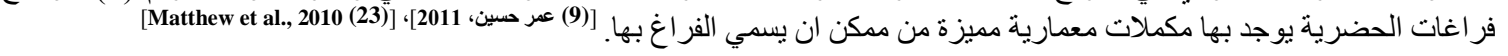




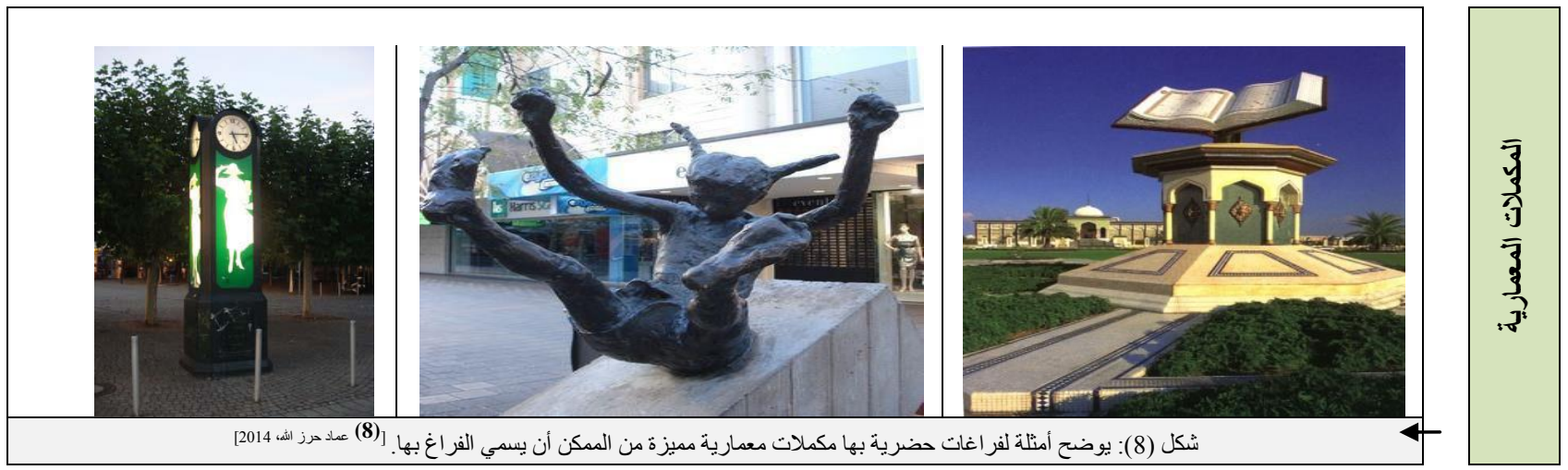

مخطط (3): يوضح المكونات المادية للفراغات الحضرية. (بتصرف الباحث)

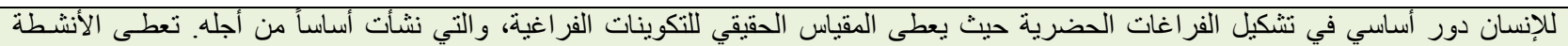

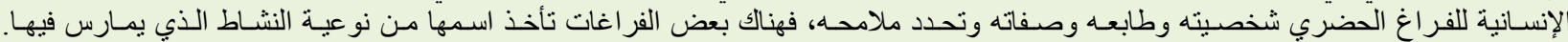

[(21) Johan Simonds, 2013]

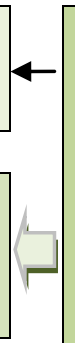

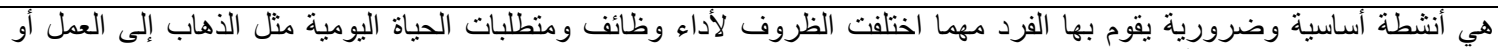

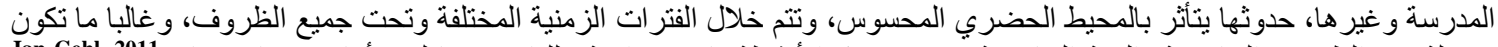

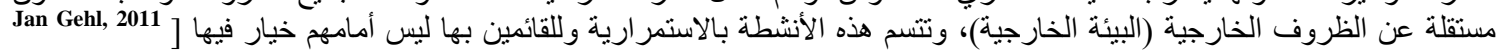

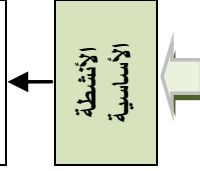

تعد الفر اغات الحضرية صنفا أساسياً من أصناف الأماكن الترفيهية المتنوعة. فللفر اغات الحضرية أهمية في ممارسة الأنشطة الإنسانية

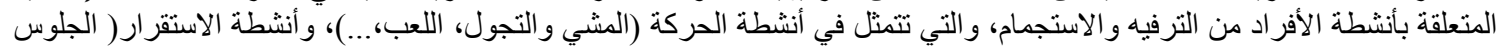

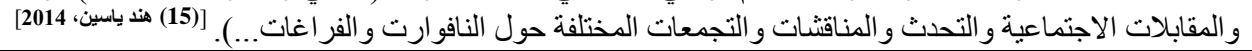
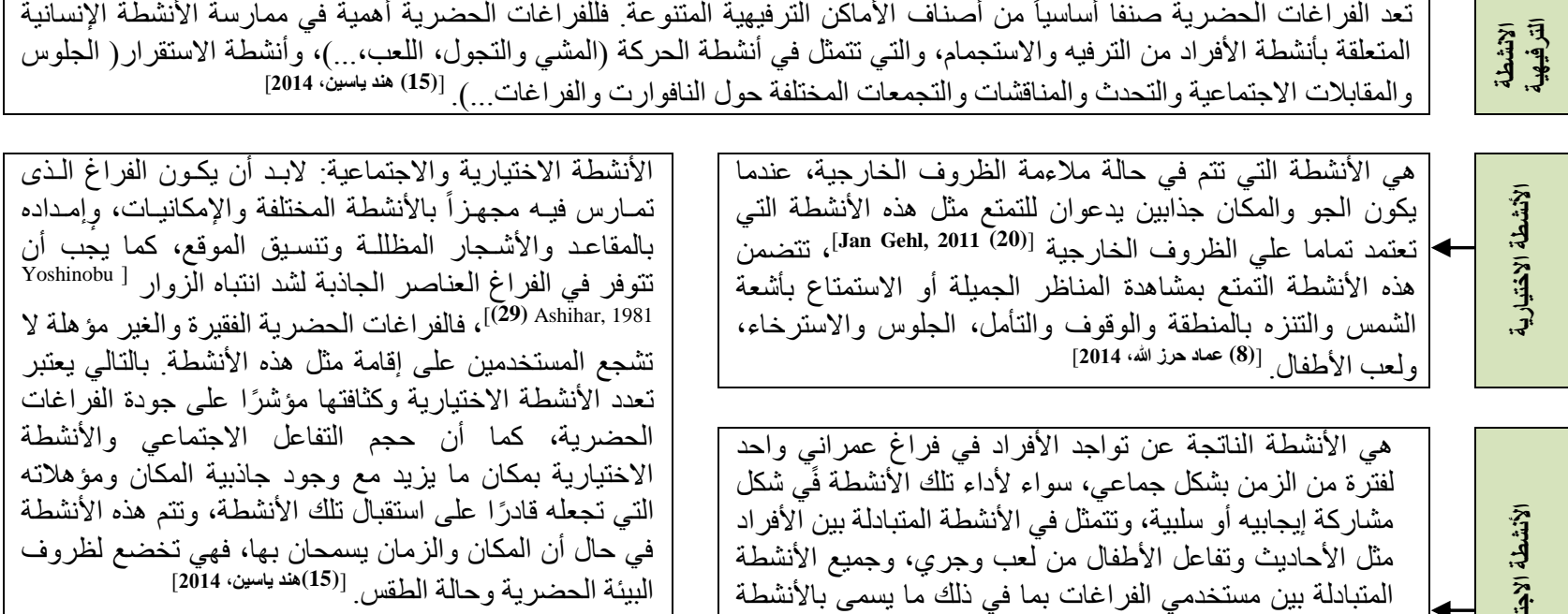

الأنشطة الاختيارية والاجتماعية: لابـد أن يكون الفراغ الأنى الأنى

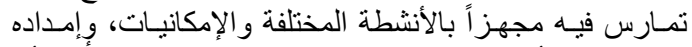

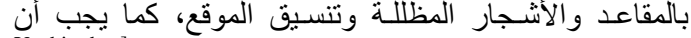

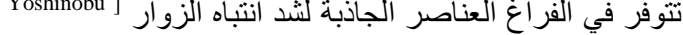

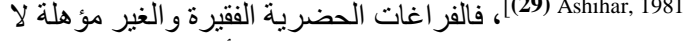

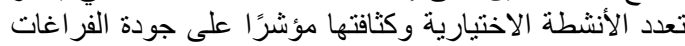

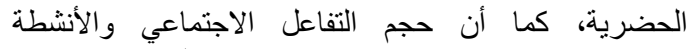

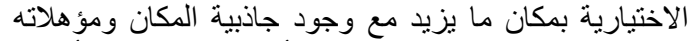

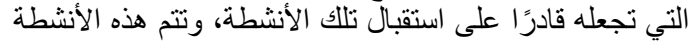

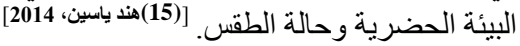
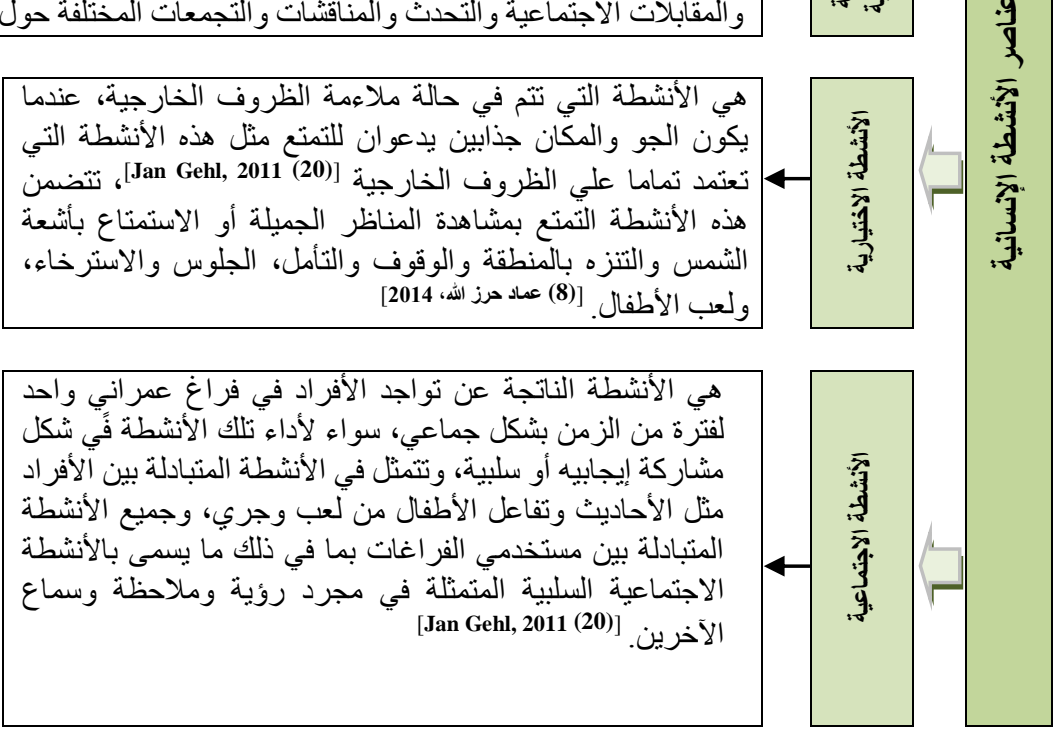

مخطط (4): يوضح عناصر الأنشطة الإنسانية للفر اغات الحضرية. (بتصرف الباحث)

الطبيعية للأشكال وحجمها ولونها ومادتها في تحديد الصفات الأساسية للفراغ

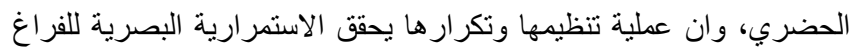

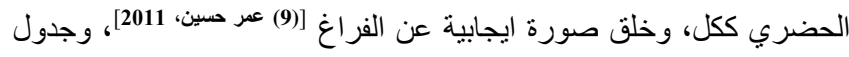
(1) يوضح خصائص مكونات الفر اغات الحضرية بصفة عنة عامة.

$$
\text { 3-5 خصائص مكونات الفراغ الحضري: }
$$

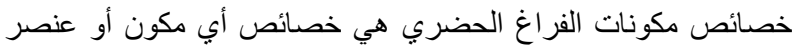

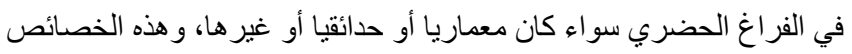

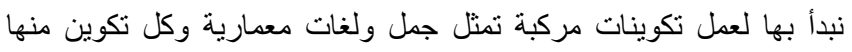

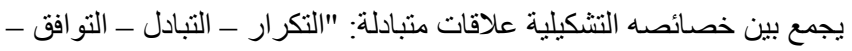

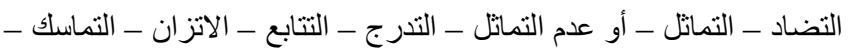

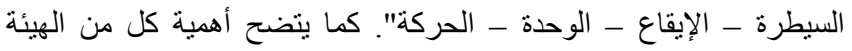




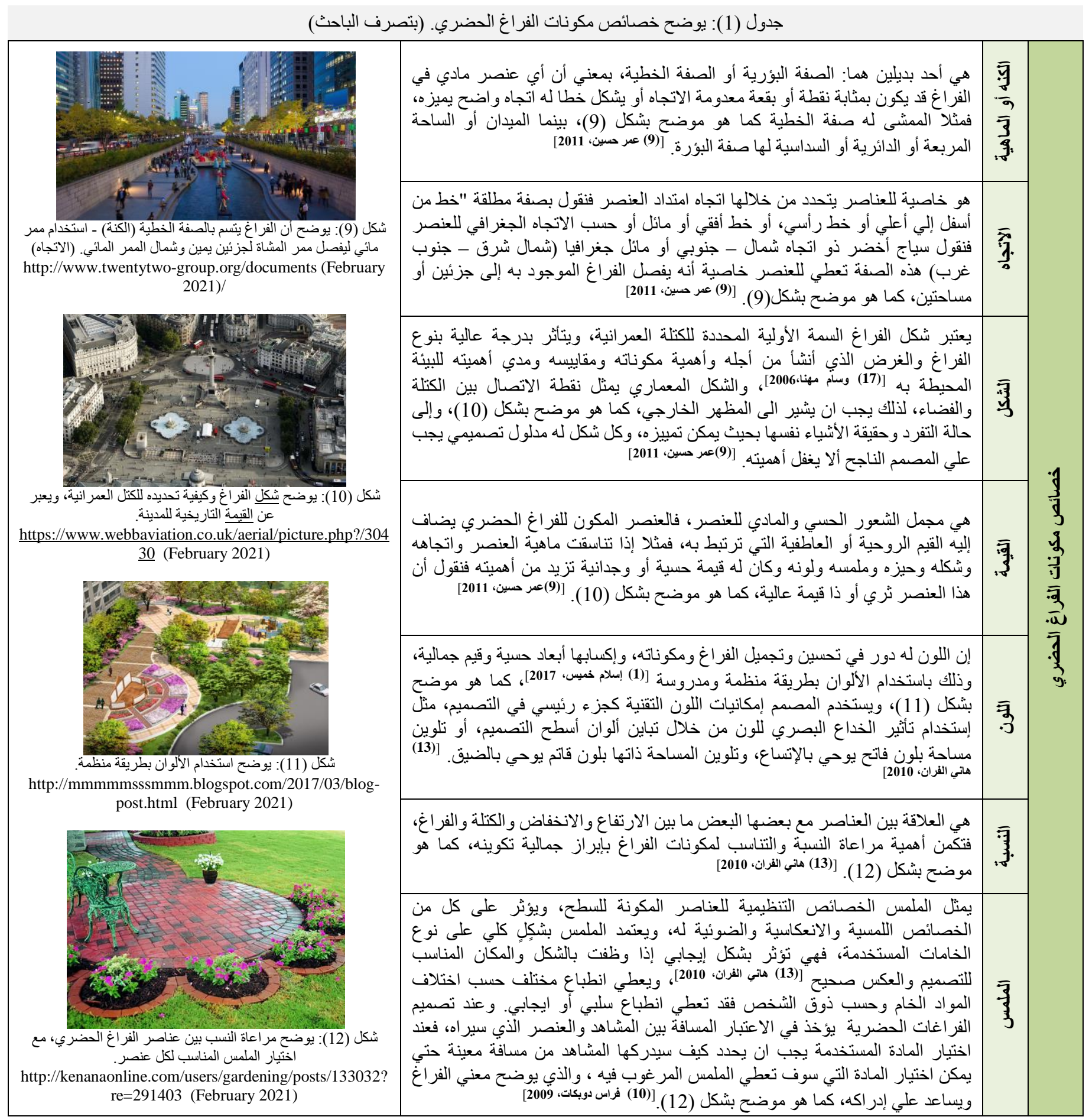

وبالتالي فإن كفاءة تصميم وتنسيق الفر اغات الحضرية يعتمد علي مجمو عة من إنال

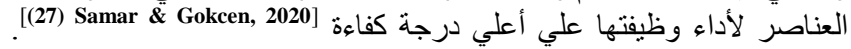

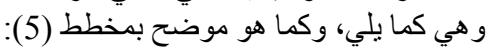

\section{6. الأداء الوظيفي للفراغات الحضرية.}

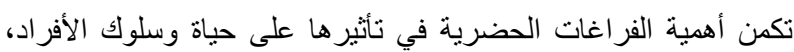

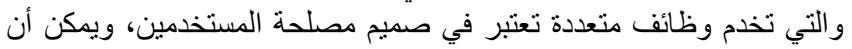

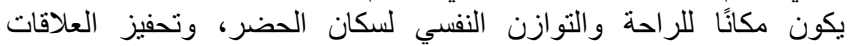

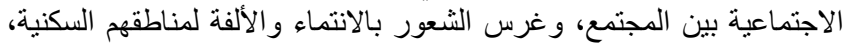




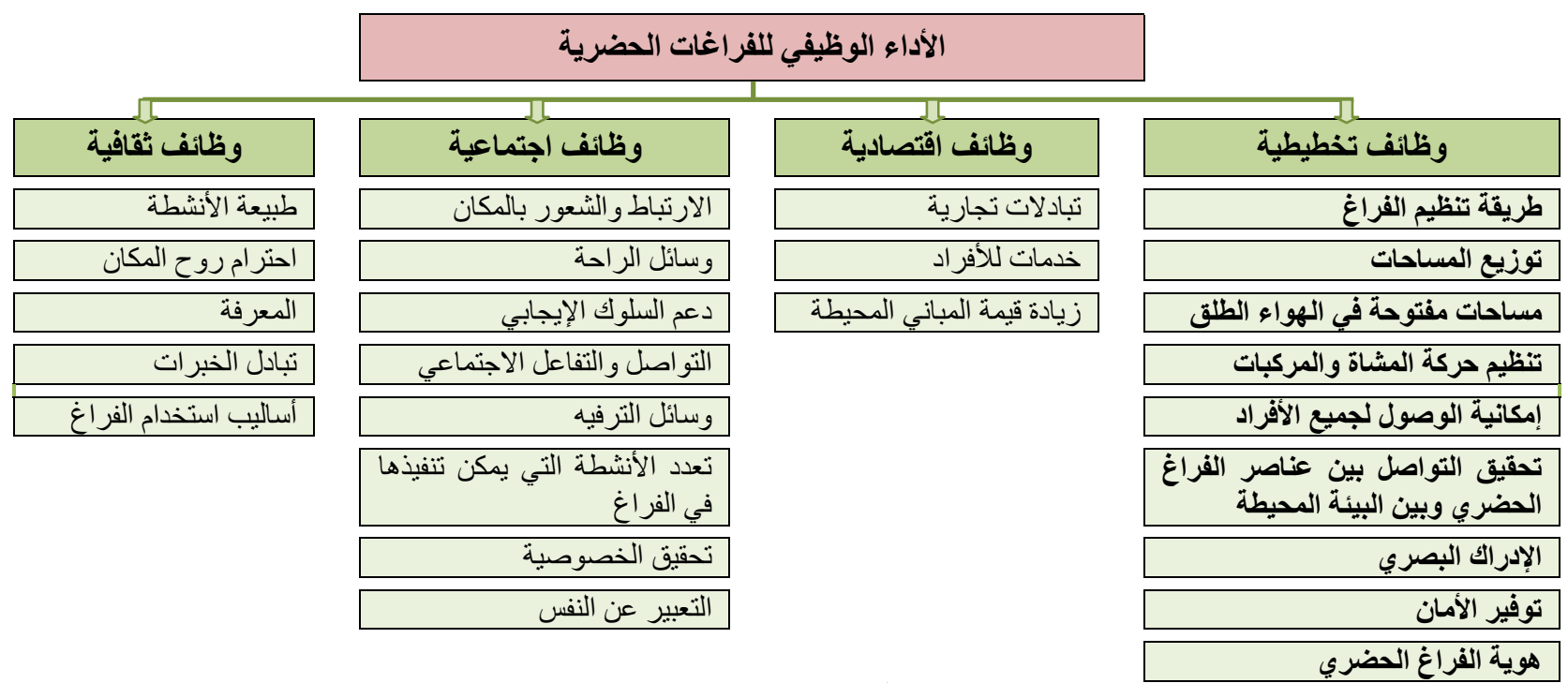

مخطط (5): يوضح الأداء الوظيفي للفر اغات الحضرية (الباحث)

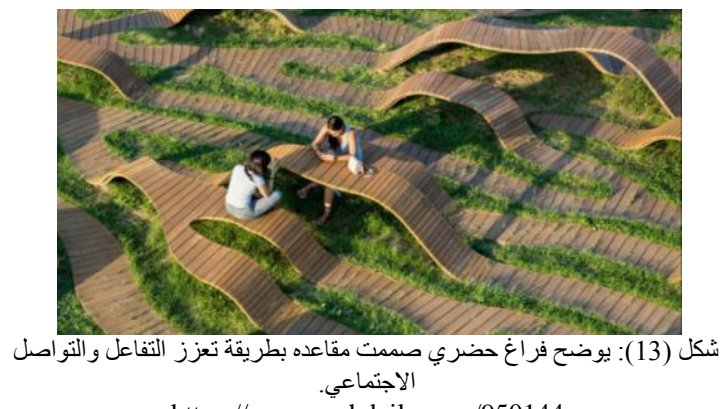

https://www.archdaily.com/950144

الالتقاء: يعتبر الفراغ الحضري أنسب مكان للتفاعل الاجتماعي و الالتقاء، ويعتبر في ذللك مثل المنزل فيساعد على إيجاد نوان نوع من الأن الاخوة

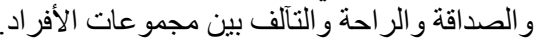

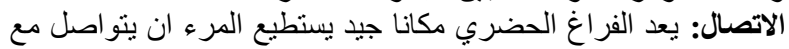

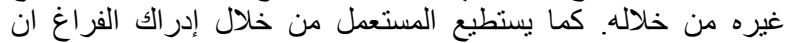

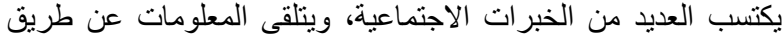

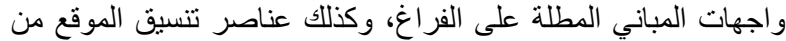

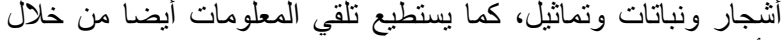

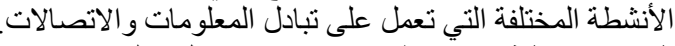

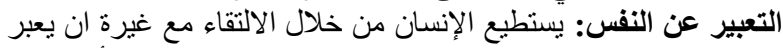

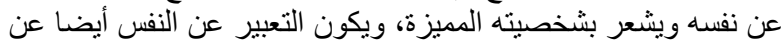

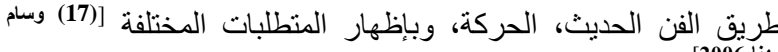

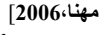

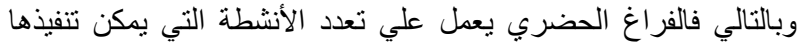

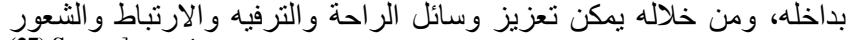

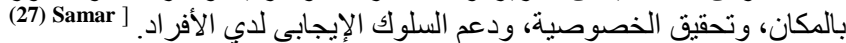

[\& Gokcen, 2020

4-6 و وظائف ثقافية

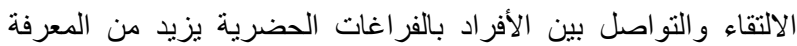

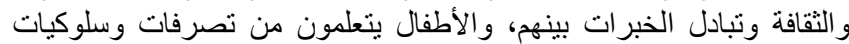

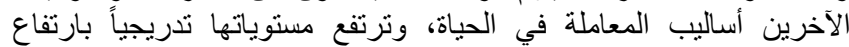

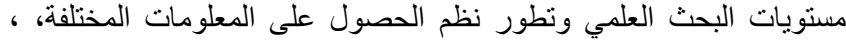

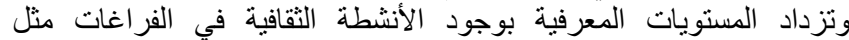
العروض والمسرحيات والاحتفالات العامة في الأعياد والمناسبة فئات الدينية
6 1 و وظائف تخطبطبة

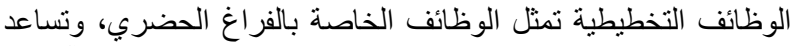

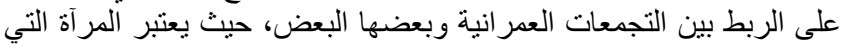

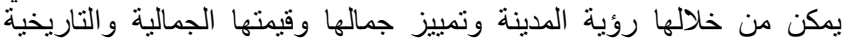

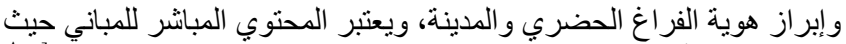

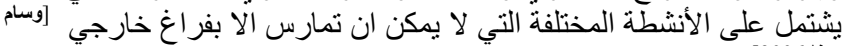

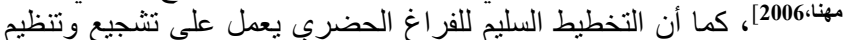

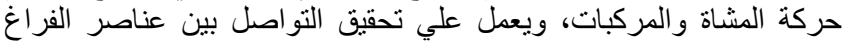

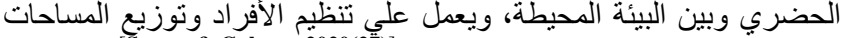
ويخلق فر اغات مفتوحة في الهو اء الطلق. [Samar \& Gokcen, 2020(27)]

6-6 وظائف (قتصادية

الفر اغات الحضرية لها دور ا اقتصاديا هاما، فهنالك تبادلات تجارية التهارية تحدث

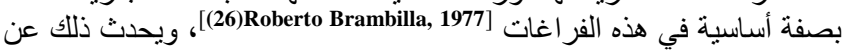

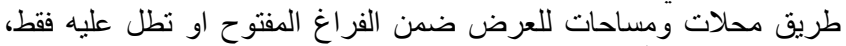

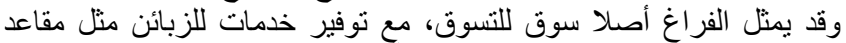

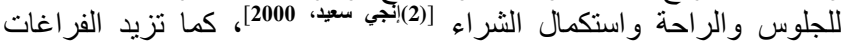

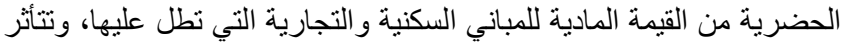

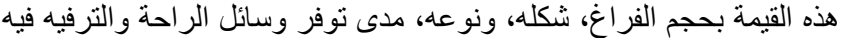

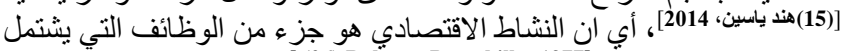

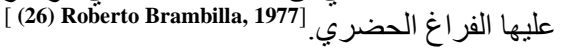

3-6 وظائف /جتماعية وترفيهية.

تعتبر الفراغات الحضرية بمختلف أنواعها بمثابة الفراغية إنات المعيشية

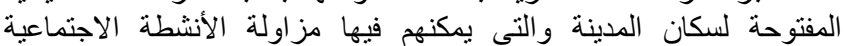

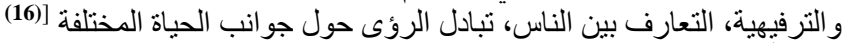

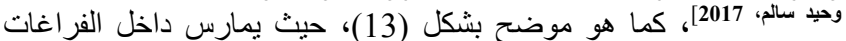
الحضرية العديد من الأنشطة الاجتماعية، والتي لا يمكن تجاهلها او الاستغناء عنها وتكون كالثالي: 

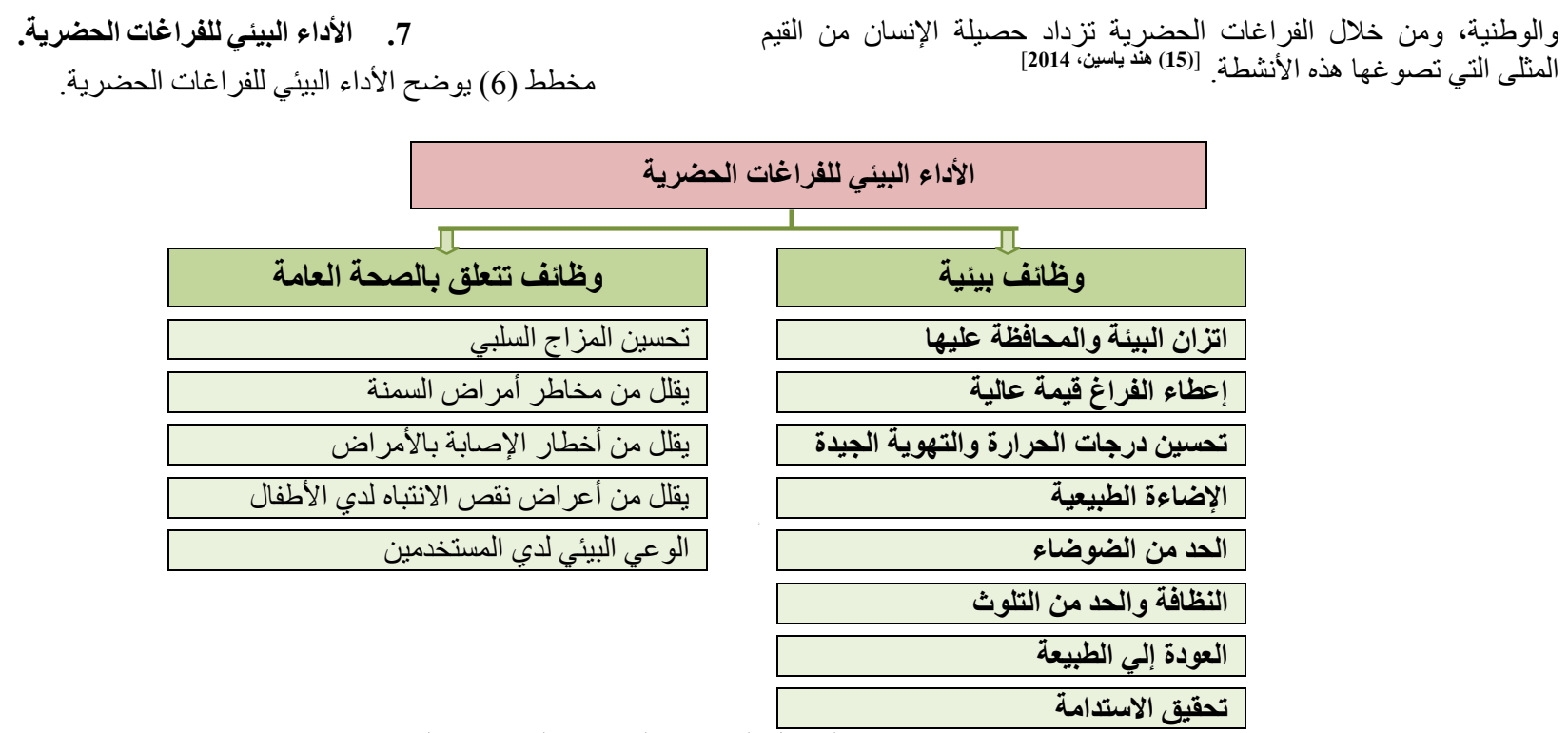

مخطط (6): يوضح العوامل البيئية في الفر اغات الحضرية (الباحث)

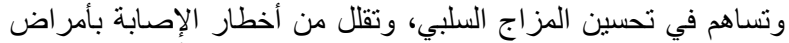

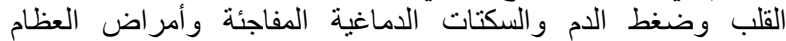

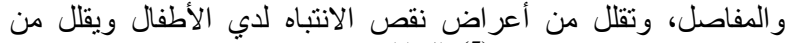

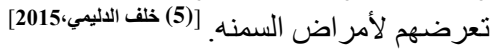

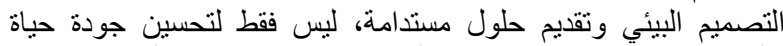

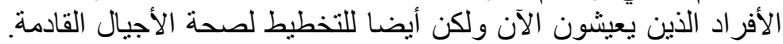

[(27)Samar \& Gokcen, 2020]

8. العناصر التي تعمل علي تحسين الأداء الجمالي للفراغ الحضري. هنالك عناصر هامة يجب ان تؤخذ في الاعتبار عند تصميم وتنفيذ

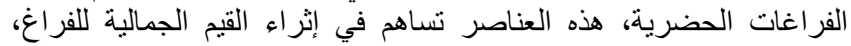

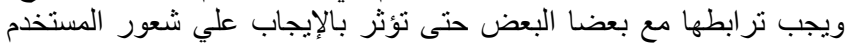

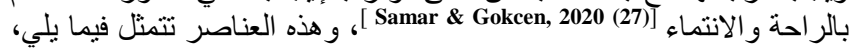

وكما هو موضتح بمخطط (7).

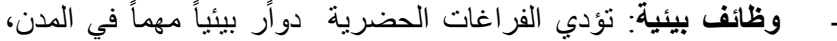

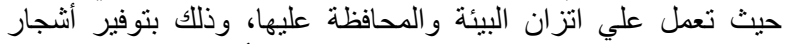

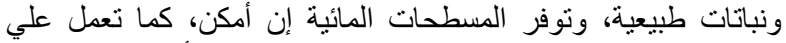

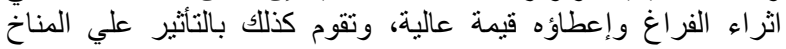

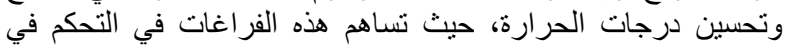

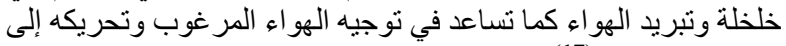

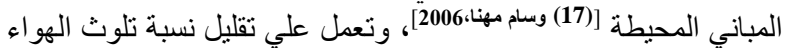

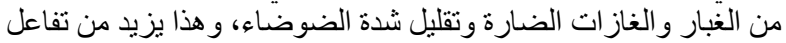

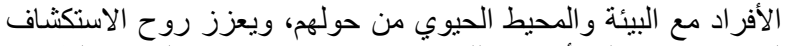

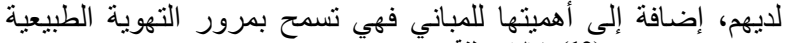

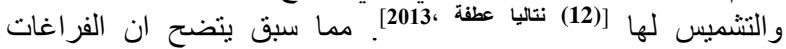

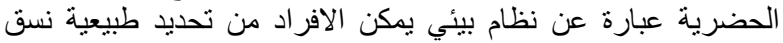

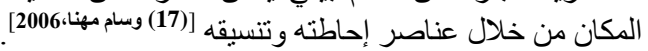

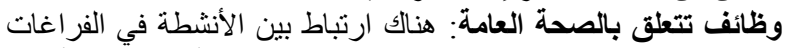

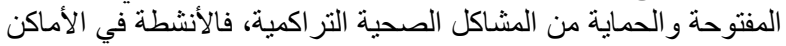

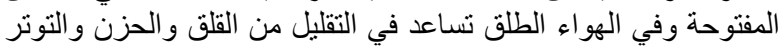

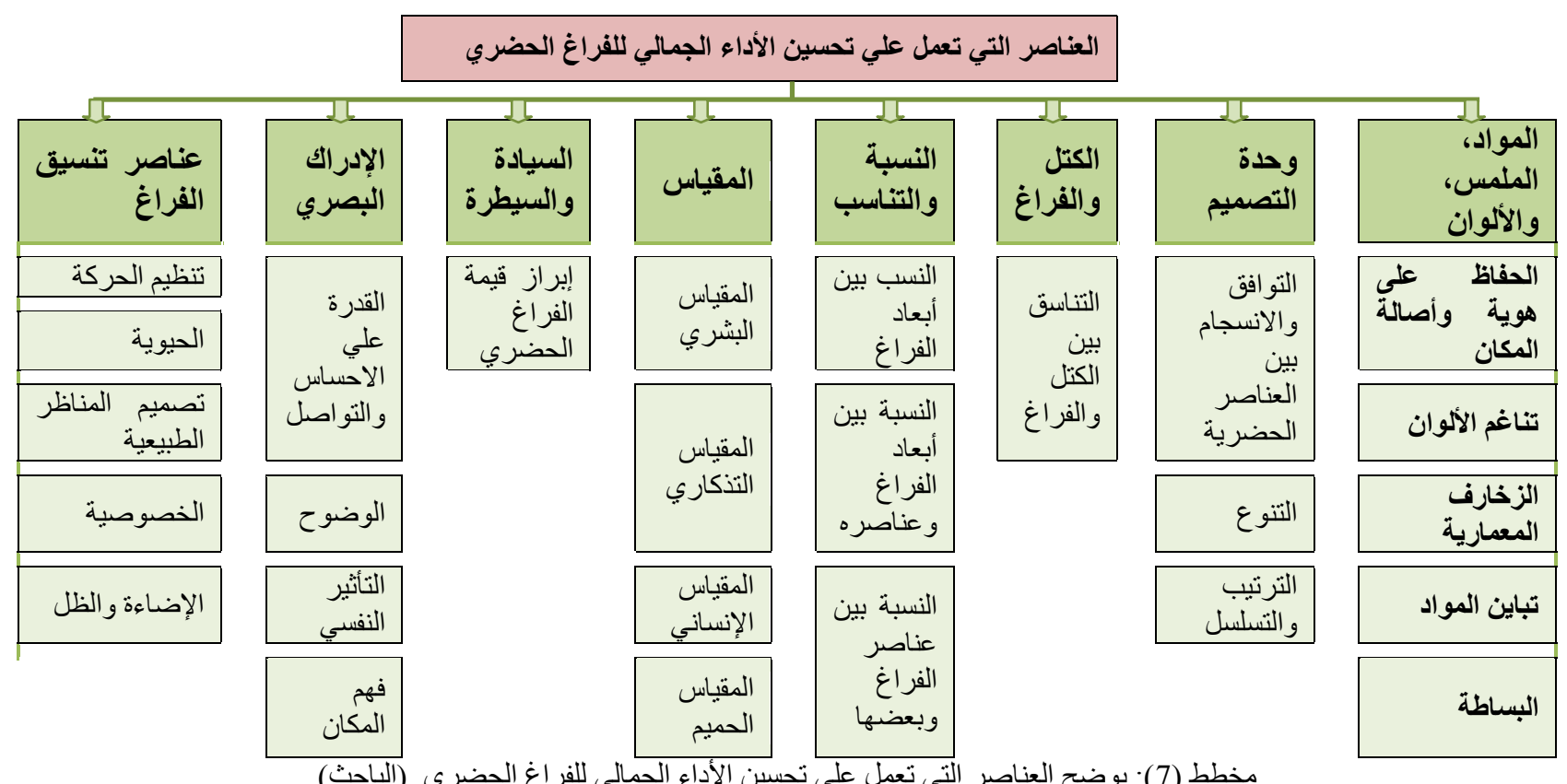


عناصره مع بعضها ما بين الارتفاع و الانخفاض و الكتلة و الفراغ، فالتصميم

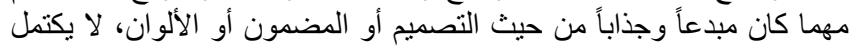

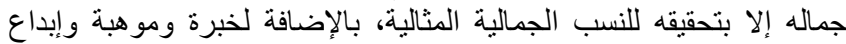

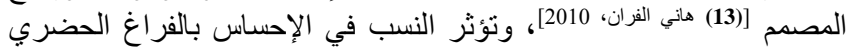

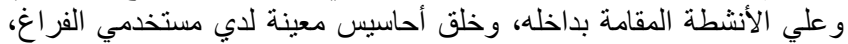

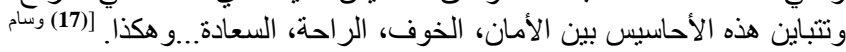

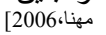

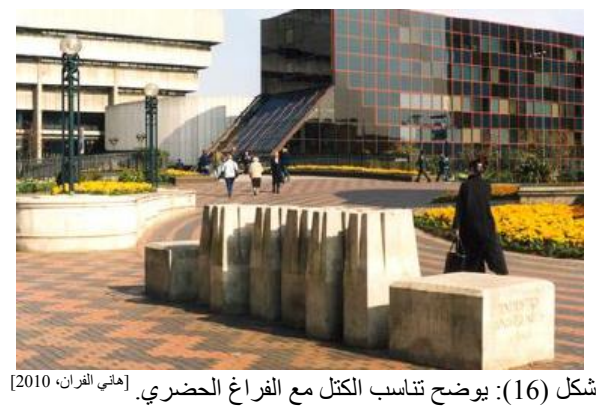

5-8

تعتبر المقاييس الإنسـانية هـي المحددات الأساسية التي تتم عليها عملية

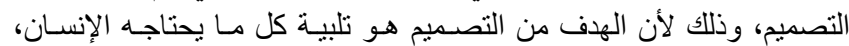

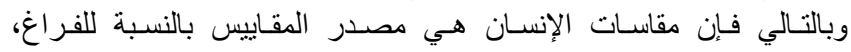

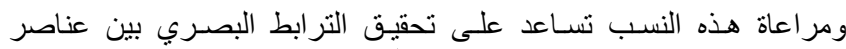

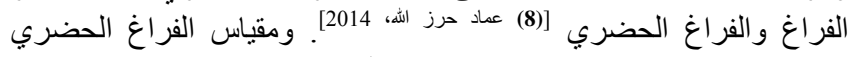
يختلف طبقا لاختلاف وظائفه ويؤكد على أهمينه، وبالتالي فانه عند تصميم

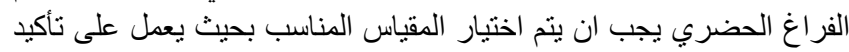

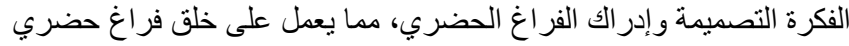

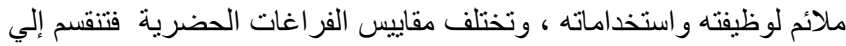

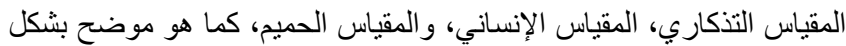

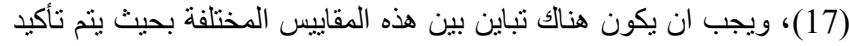
كل مقياس، كما يجب أيضا ان يكون هنالك جمع ونرابط بئ بين هذه الئ المقاييس

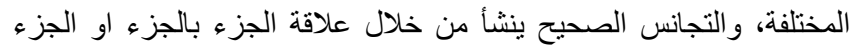

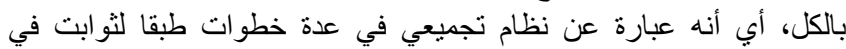

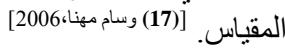

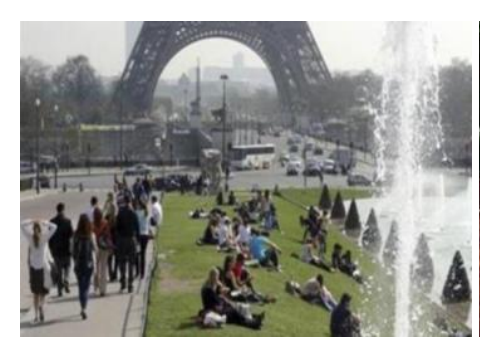

المقياس التذكاري

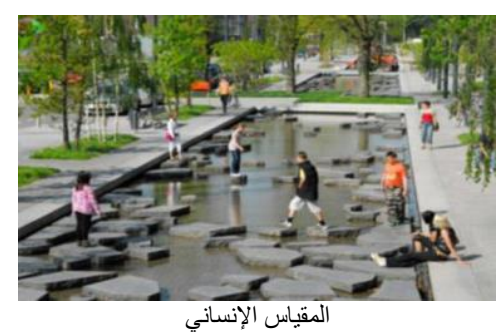
شكل (17): يوضح أنواع مقاييس الفر اغ. [3(3) جمال عبد الحميد وآخرون، 2019]

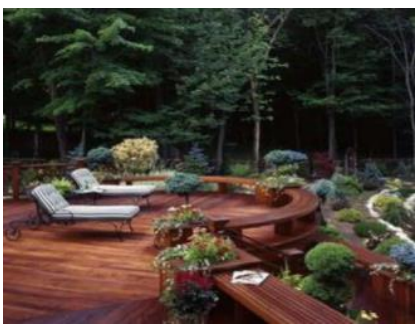

المقياس الحميم
1-8 المو/د، الملمس، الألوان

تؤثر المواد المستخدمة في مكونات الفراغات الحوات الحضرية على شكلها

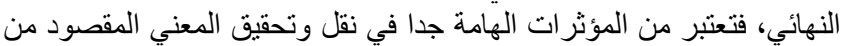

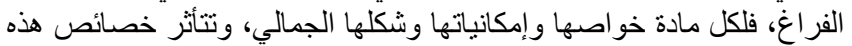

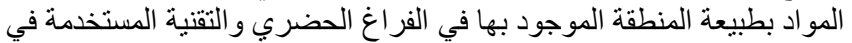

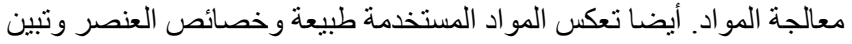

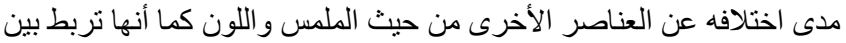

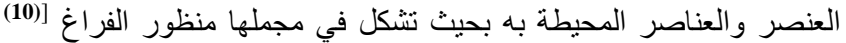

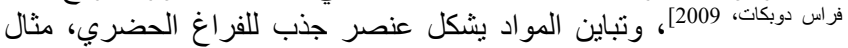

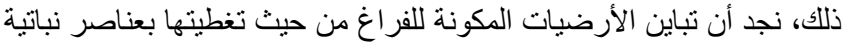

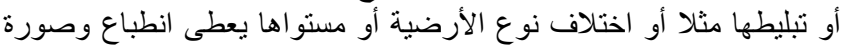

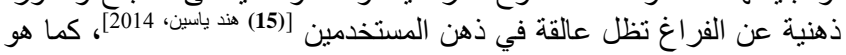

موضح بشكل (14).

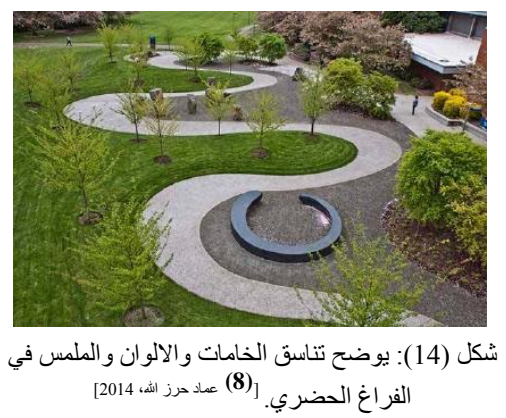

2-8 وحدة التصميم

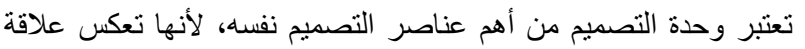

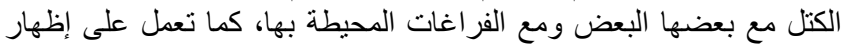

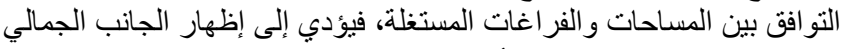

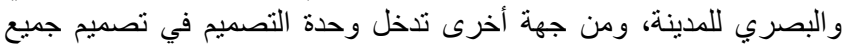

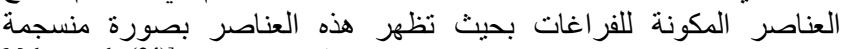

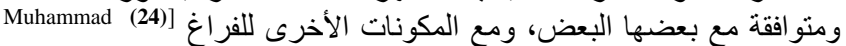

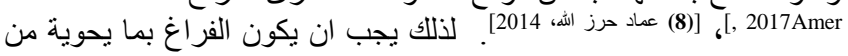

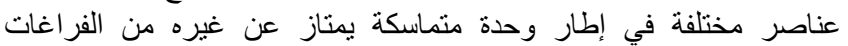

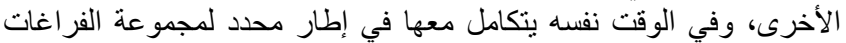
المحيطة. [2(2) أنجي سعيد، 2000]

3-8

تعد الكتلة والفراغ من أهم المحددات والقيم التشكيلية لتصميم الفراغ

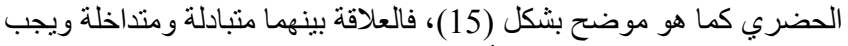

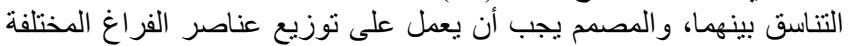

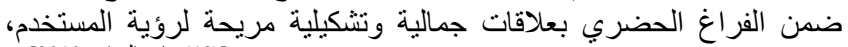
ويعتمد التشكيل الفر اغي علي المقياس الإنساني و الحركة. [(13) هاني الفران، 2010]

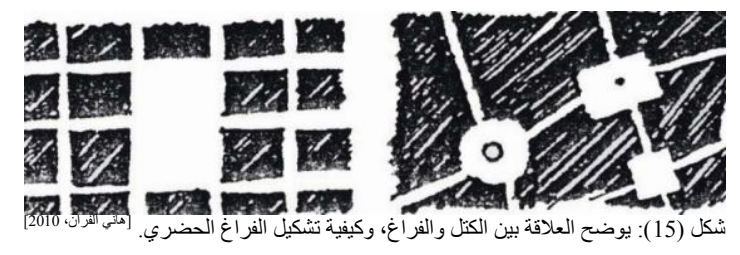

4-8

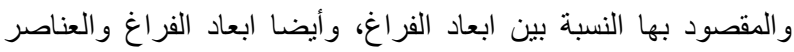

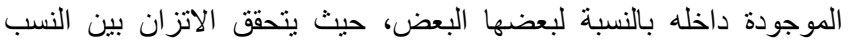

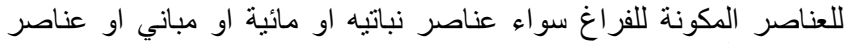

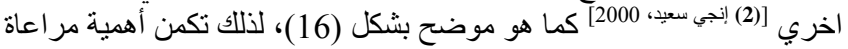
النسبة والتناسب في تصميم الفراغ الحضري بإبراز جمالية تكوينه و علاقة الهية 


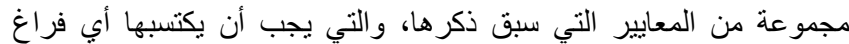

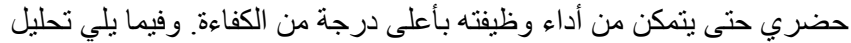

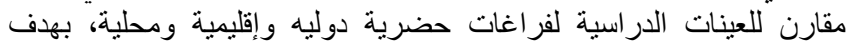

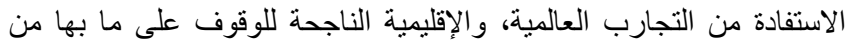

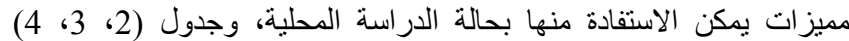
يوضح تحليل مقارن للأداء الوظيفي والبيئي والجمالي بالفرانية والفات محل الدر اسة:

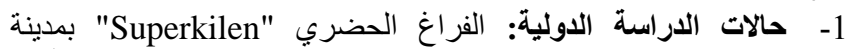
Copenhagen

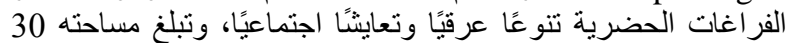

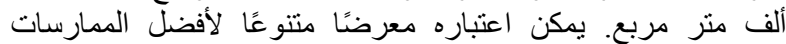

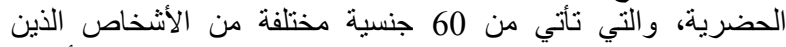

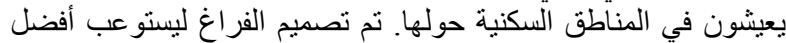

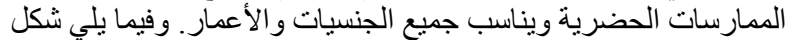

(20) يوضح الدخطط العام للفر اغ الحضري "Superkilen".

[https://blogs.iadb.org/ciudades-sostenibles/en/public-space-for-all, November 2020] ، [https://www.dezeen.com/2012/10/24/superkilen-park-by-big-topotek1-and-superflex, November 2020]

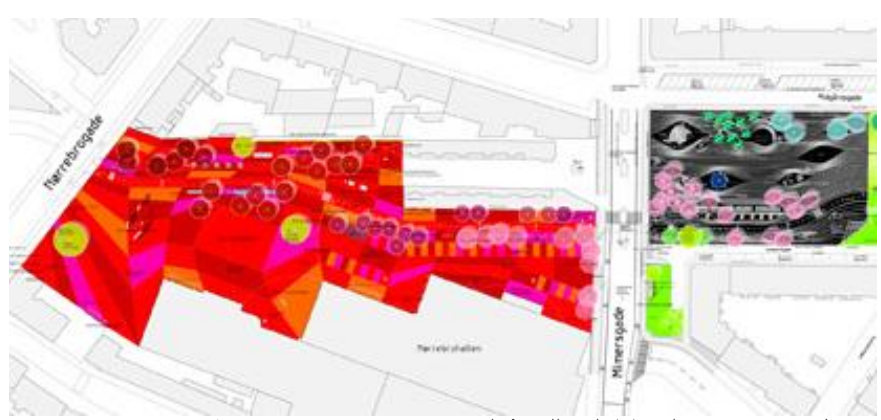

شكل (20): يوضح المخطط العام للفر اغ الحضري "Superkilen" بمدينة Copenhagen بالدنمارك.

[https://www.dezeen.com/2012/10/24/superkilen-park-by-big-topotek1and-superflex, November 2020]

2- الات الدراسة الإقليمية : الفراغ الحضري الكائن بثارع الملك فيصل

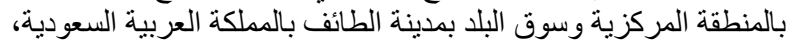

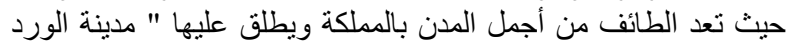
و الألوان" و إحدى الوجهات السياحية في المملكة وأهم الددن التجارية

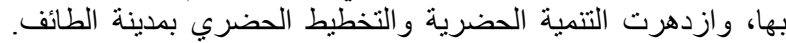

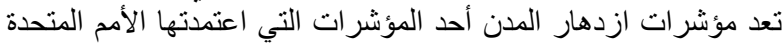

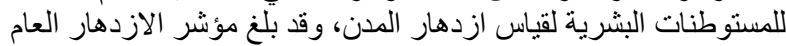

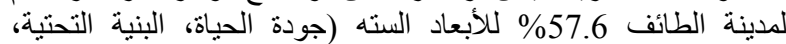

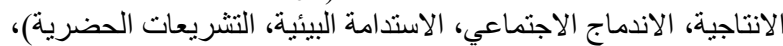

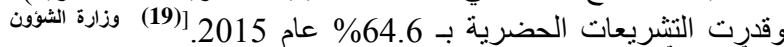

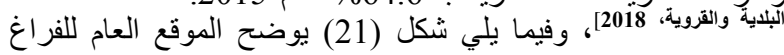
الحضري الكائن بشارع الملاك فيصل بالطائف.

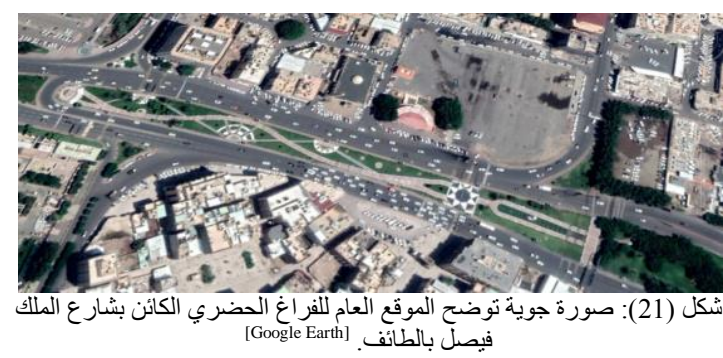

3- حالات الدراسة المحلية: الفراغات الحضرية الكائنة بالقاهرة الجديدة

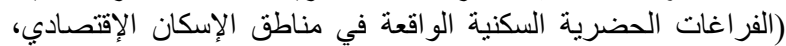

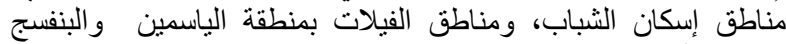

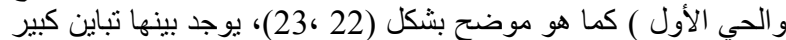
في المستوي المادي والاجنماعي، وعند النظر إلي الفراغات نجد أنها
6-8 - - السيادة والسبطرة.

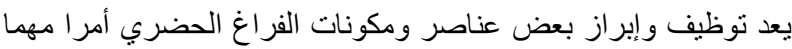

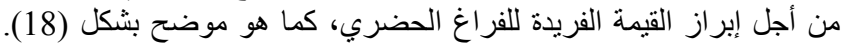
[, 2017 (24)Muhammad Amer]

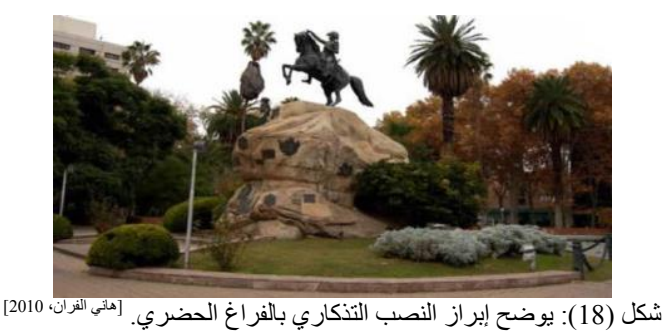

$$
\text { 7-8 الإدراك البصري للفراغ الحضري }
$$

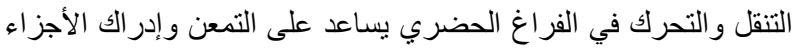

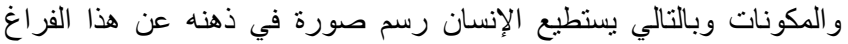

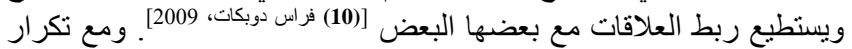

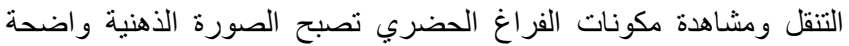

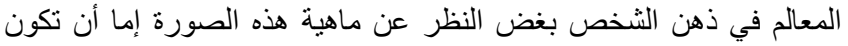

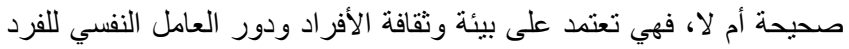

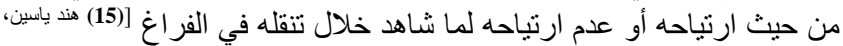

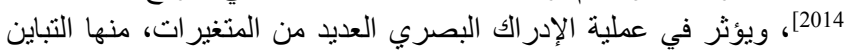

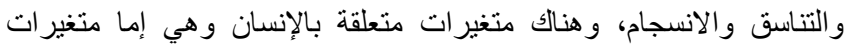

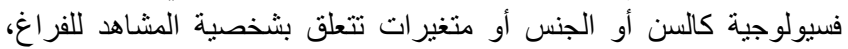

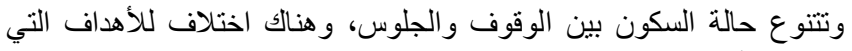

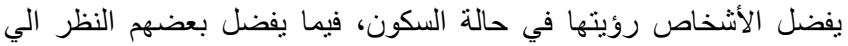

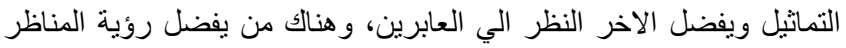

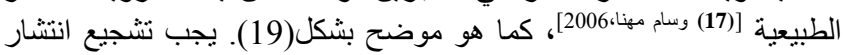

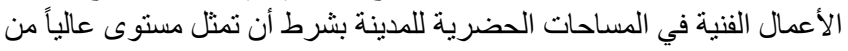

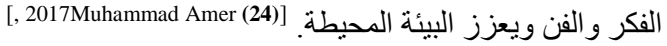

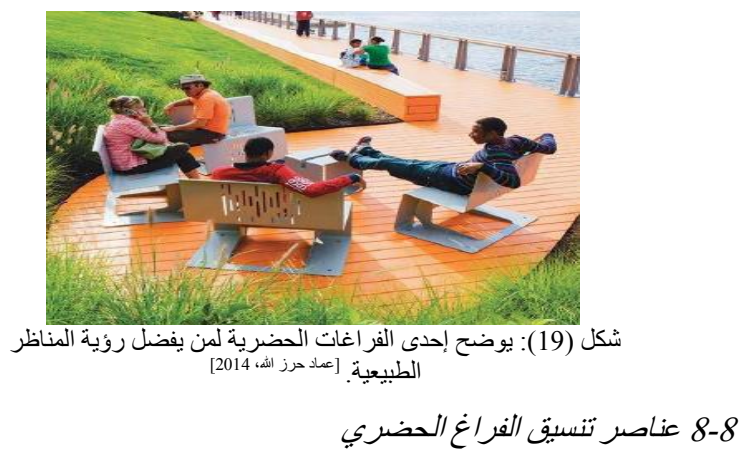

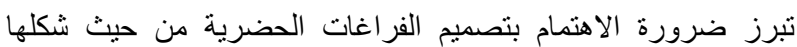

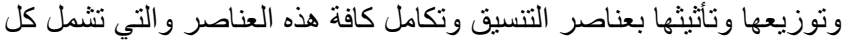

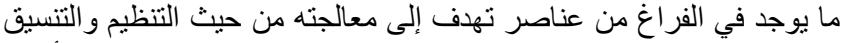

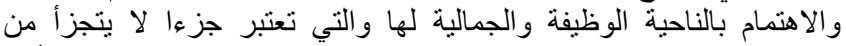

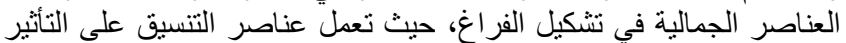

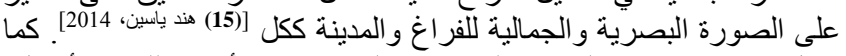

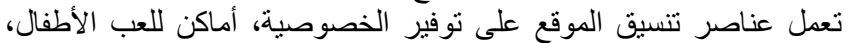

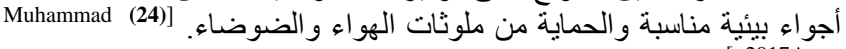
[, 2017Amer

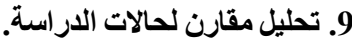

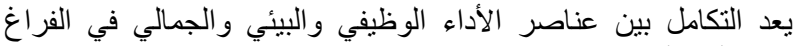

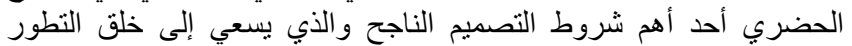

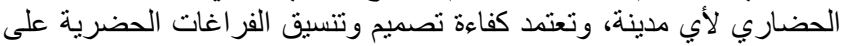




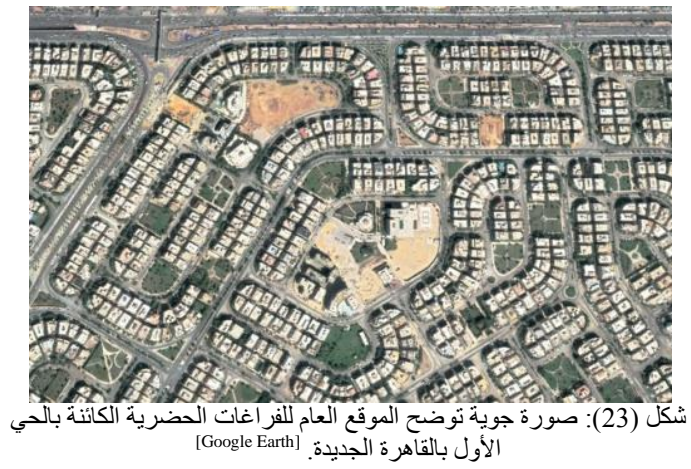

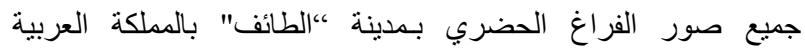

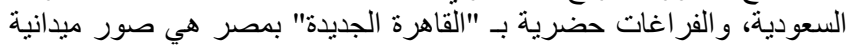

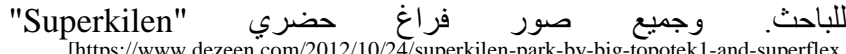
November 2020]
مختلفة اختلافا كبيرا، سواء من ناحية نوعية المباني المحيطة بها الإنها

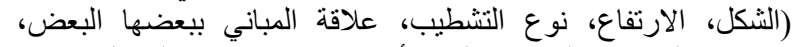

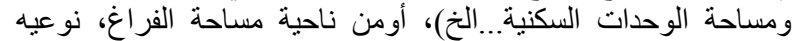

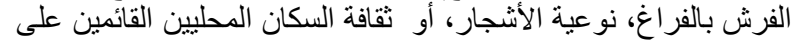
رعايتها.

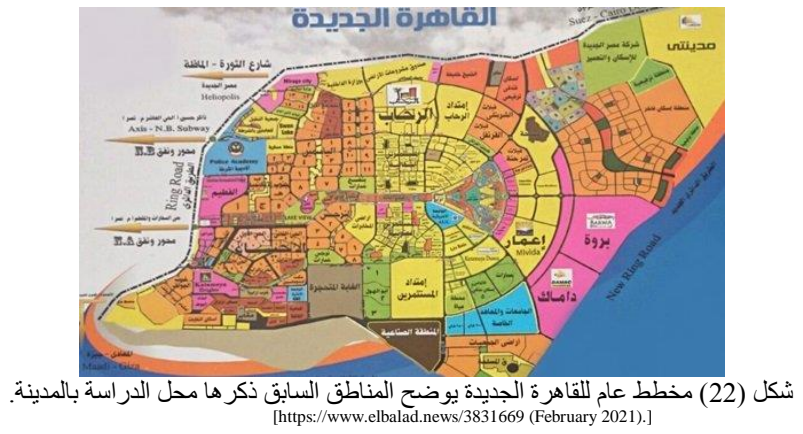

جدول رقم (2): تحليل مقارن للأداء الوظيفي بالفر اغات محل الدراسة.

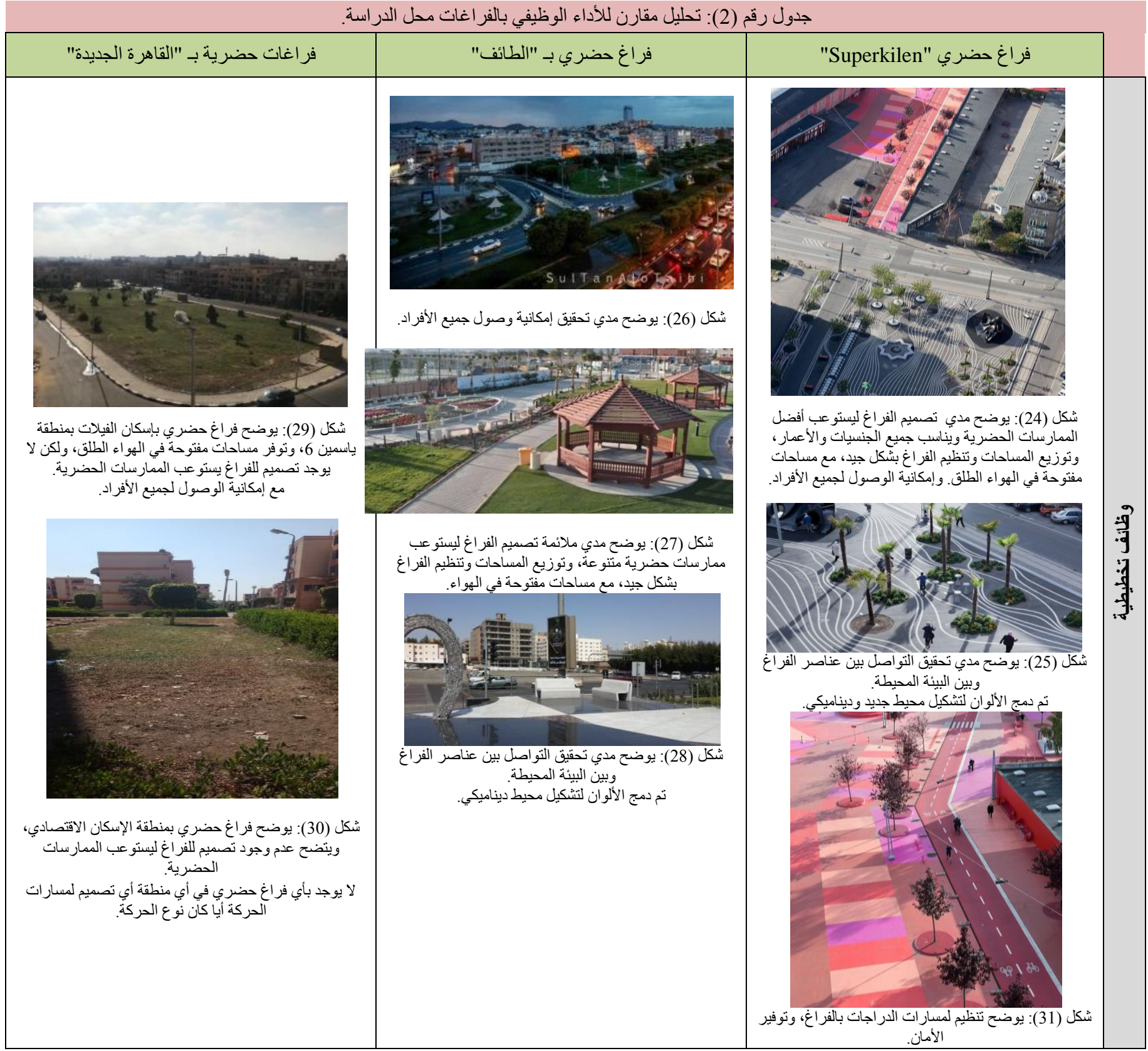




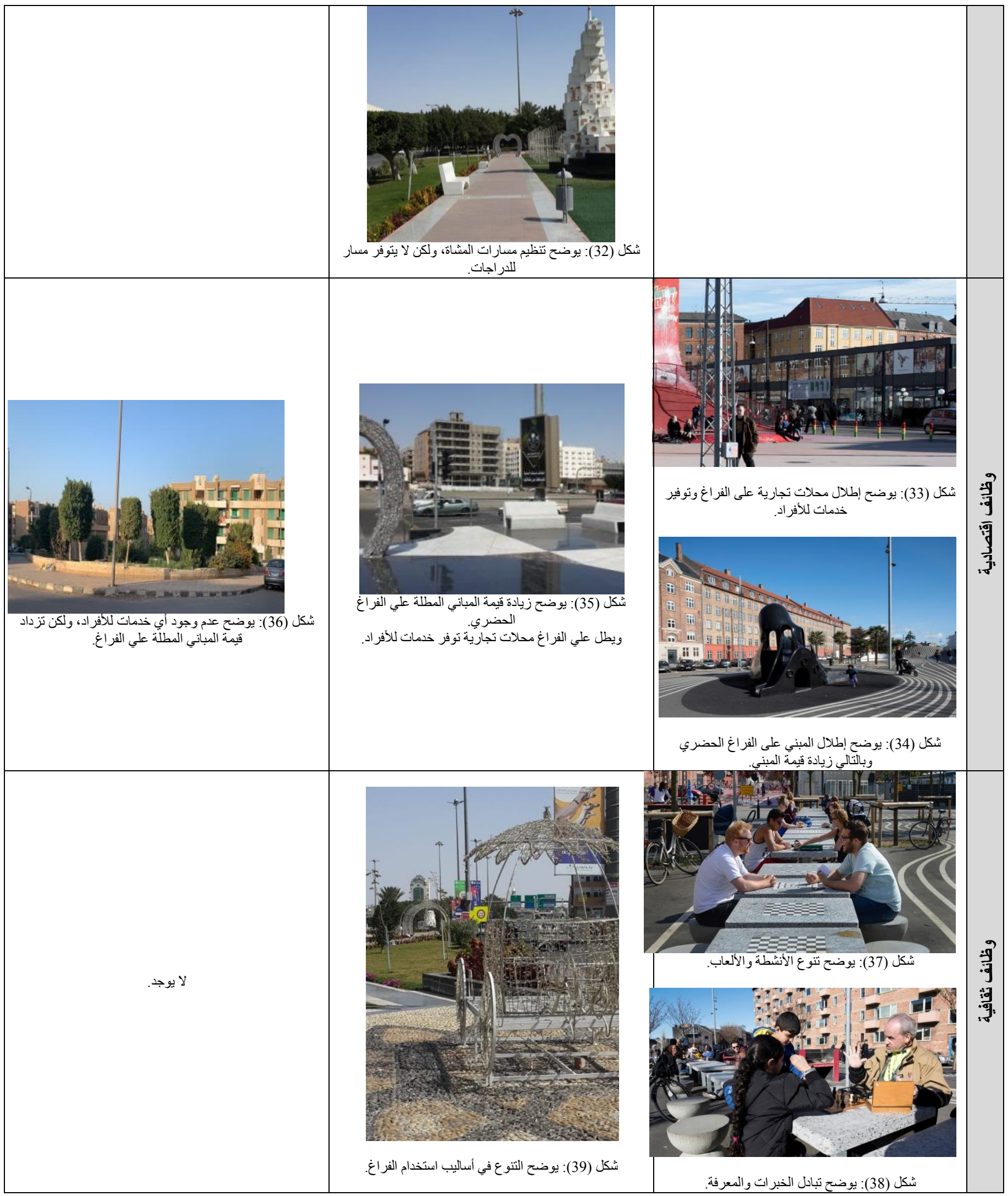




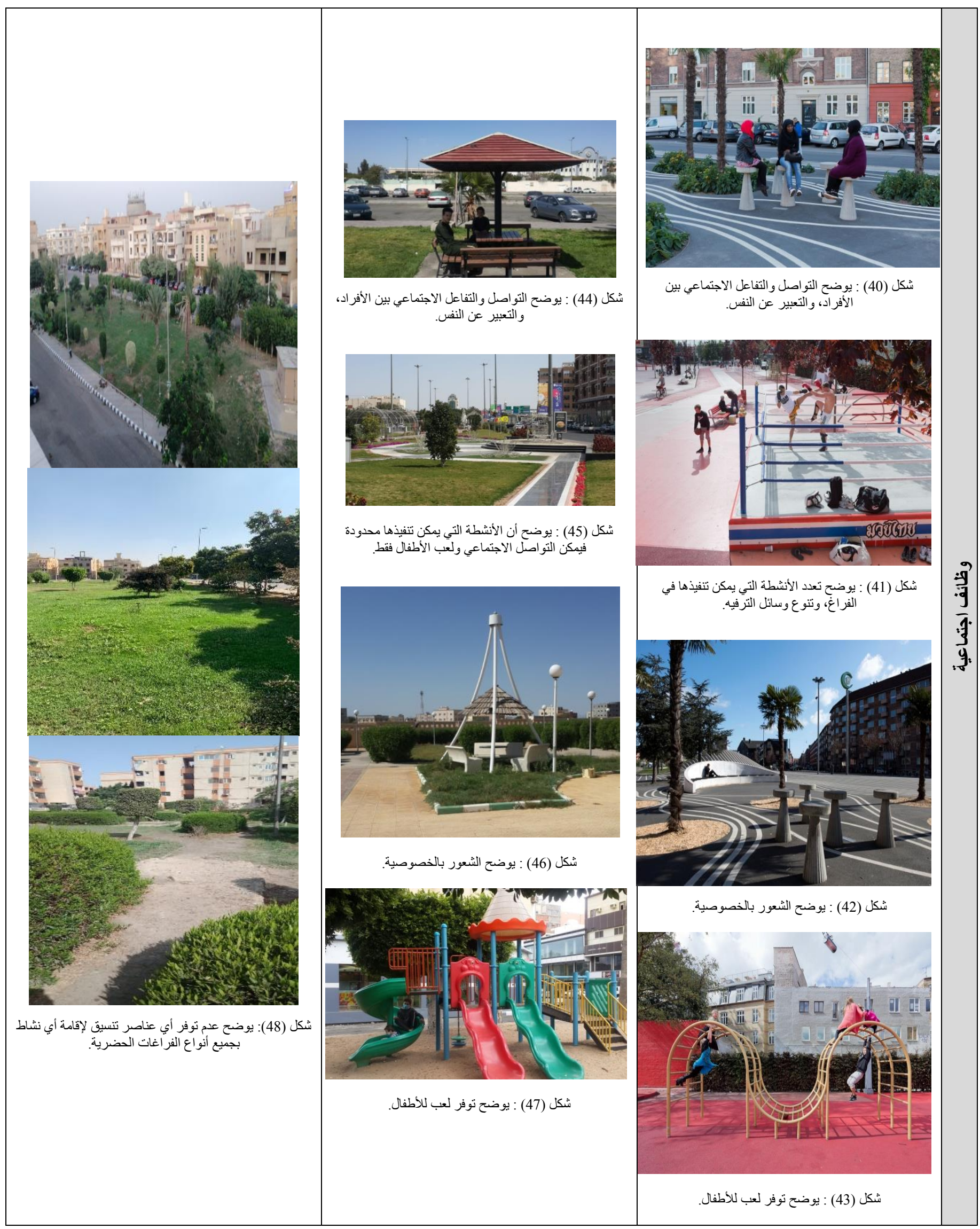




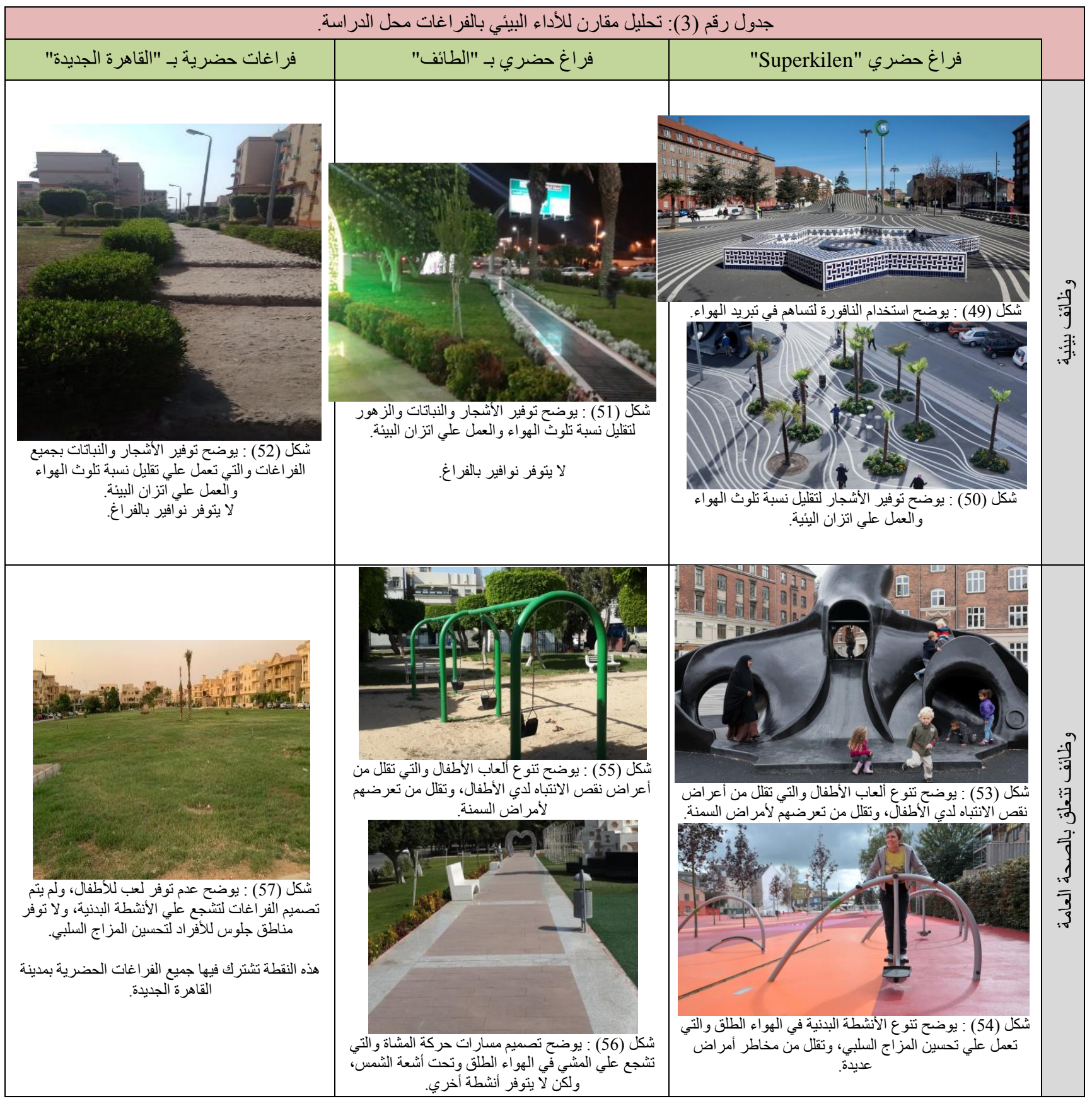

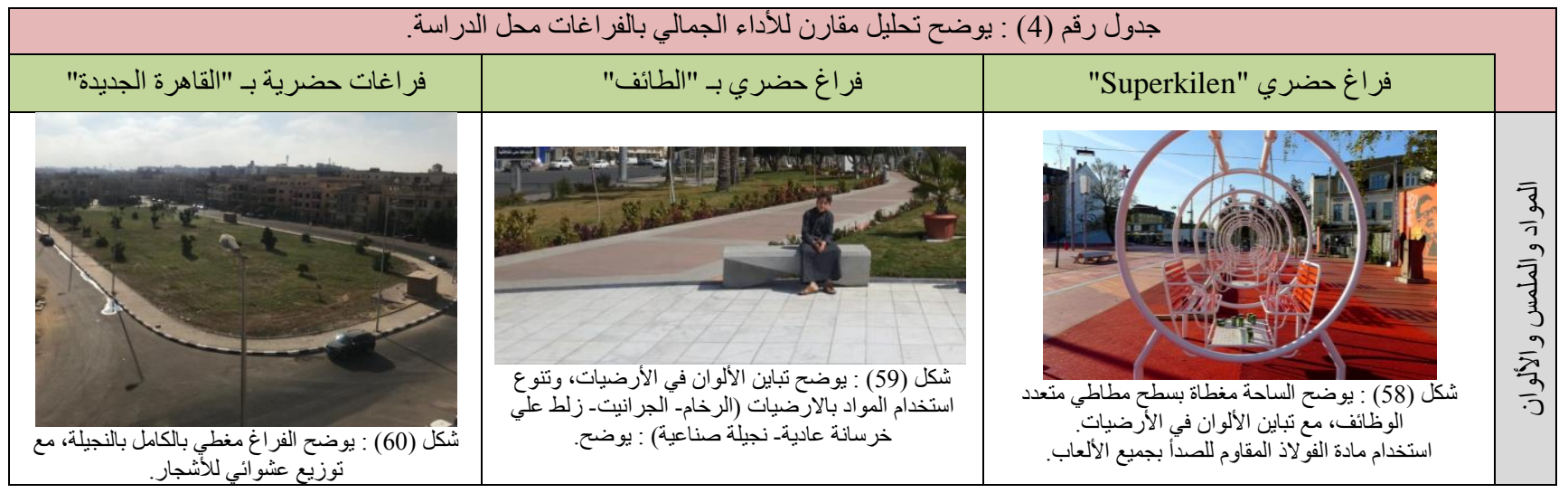




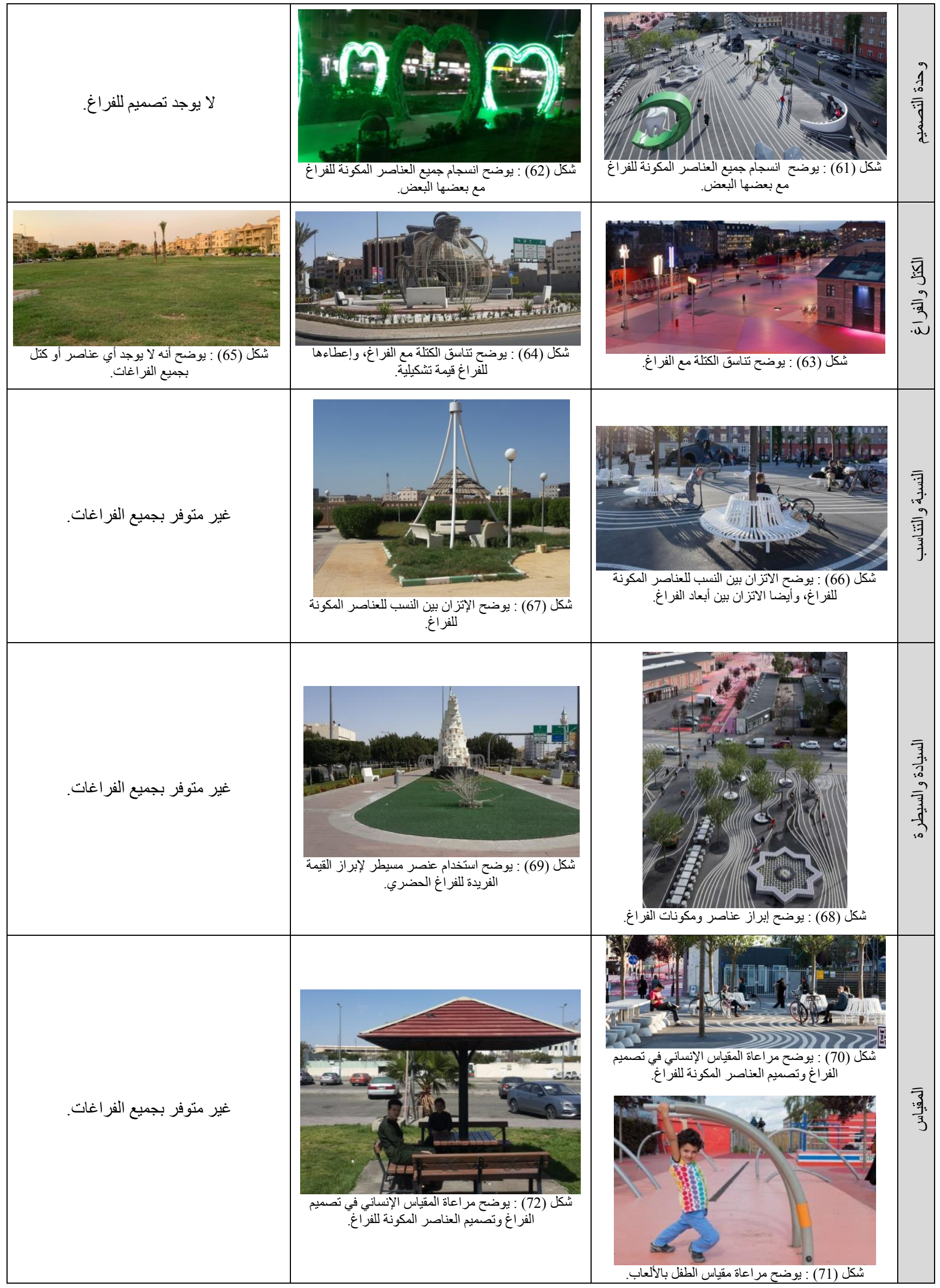




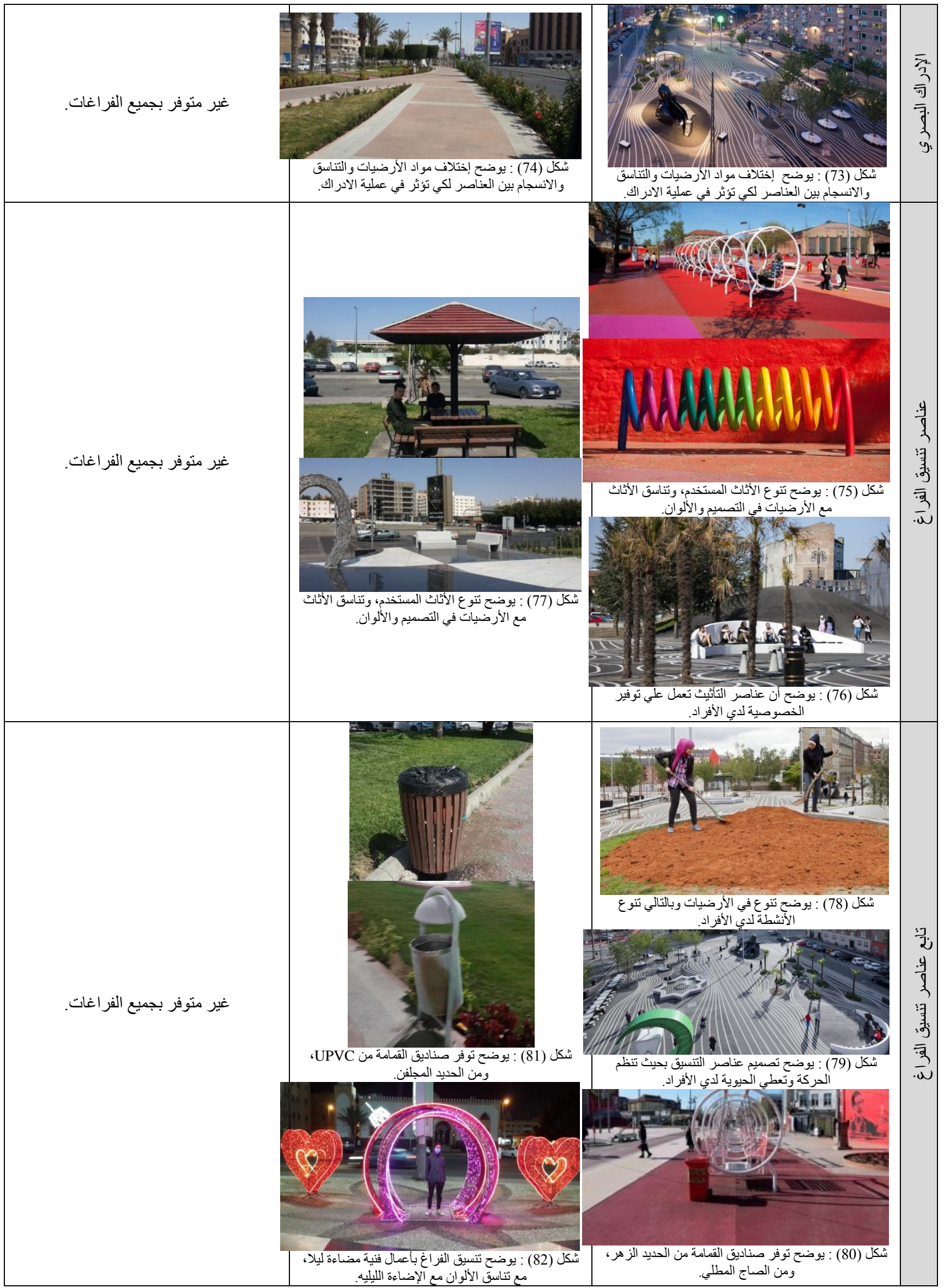




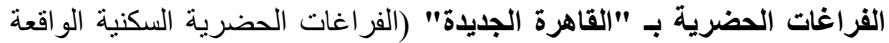

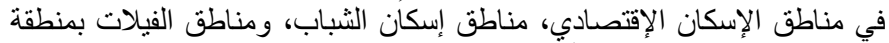

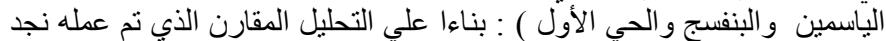

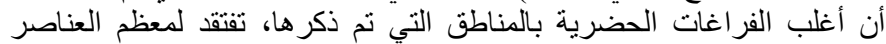

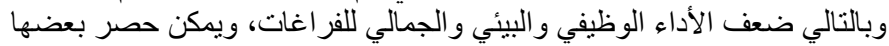

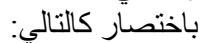

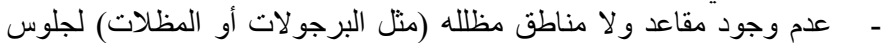

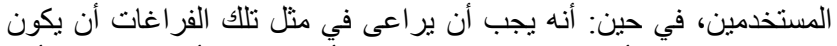

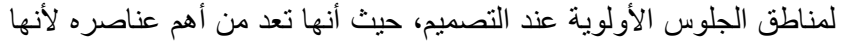

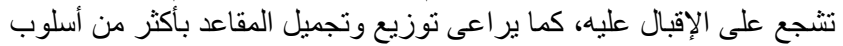

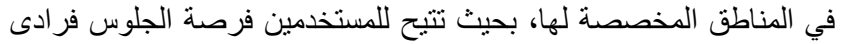

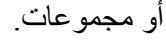
كثافة التشجير غير كافية، فنجد مساحات شاسعة معرضة لأشعة الثمس التارس

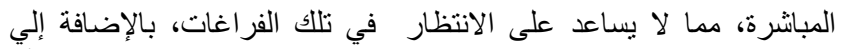

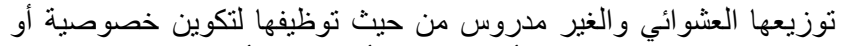

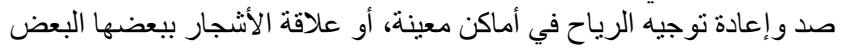

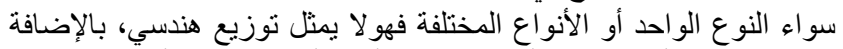

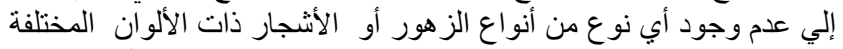

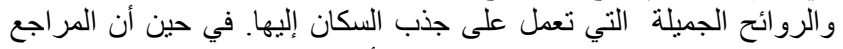

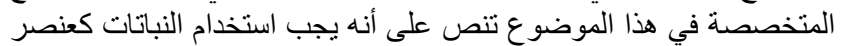

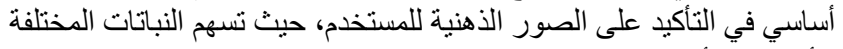
الألوان والأحجام في رسم انطباع خاص التص لدى المستخدم من خلال لون لون النباتات و الملمس و الإن ائحة. غالبية الأرضيات و والأرصفة من الخرساتة والثة الغير جيدة من حيث الجودة

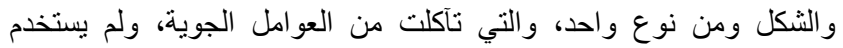

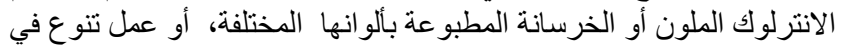

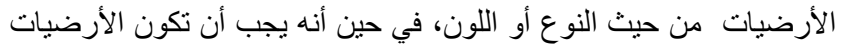

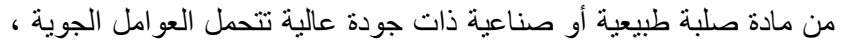

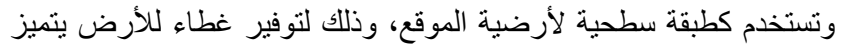

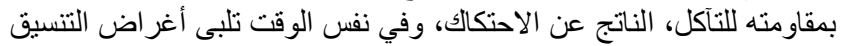

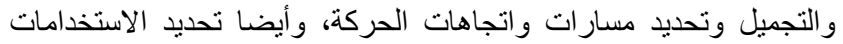

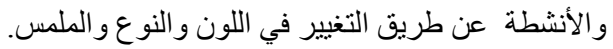

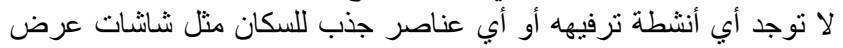

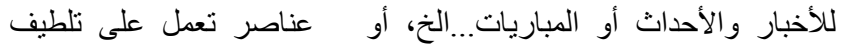

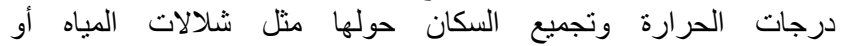
النافورات...الخ، حيث تعد العناصر المائية واحده من المكونات الأساسية لعمليات تنسيق الموقع.

عدم وجود أعمدة إنارة بداخل الفراغات نهائيا وبالتالي تصبح مظلمة ليلا

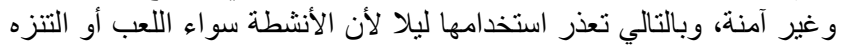
غالبا ما تمارس ليلا. لا يوجد أماكن مخصصه للأطفال، بالإضافة إلى عدم وجود ألعاب أو أنشطة

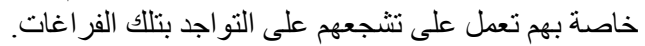

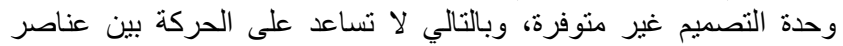

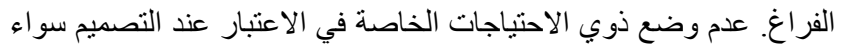

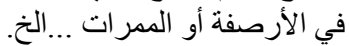
تلف الأشجار والنجيلة نتيجة عدم وجود من يقوم بأعمال الري والتهذي التذيب

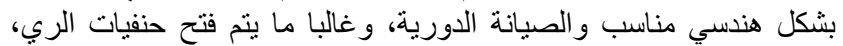
وتركها مفتوحة لأكثر من يوم على فترات مختلفة، مما أدي إلى تدهور الئة البئئة

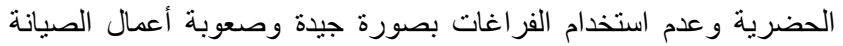
وارتفاع تكلفتها. عدم تخصيص ممرات لممارسة رياضية المشي، ولا يوجد أكثاك للكتب

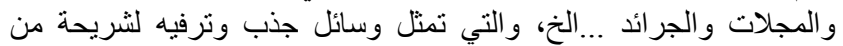
السكان المحليين. عدم وجود صناديق قمامة بالفراغات الحضرية. واستخدم السكان المحليين و غير هم الفر اغات الحضرية كمكان لتجميع القمامة ومخلفات البناء.

\section{0. نتائج التحليل المقارن لحالات الاراسة.}

نتيجة للاراسة النظرية تم الوصول للعناصر التي تعمل علي تحسين الأداء

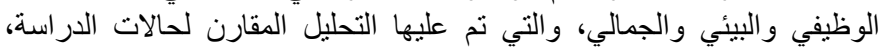

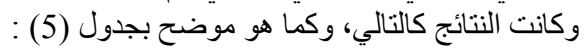

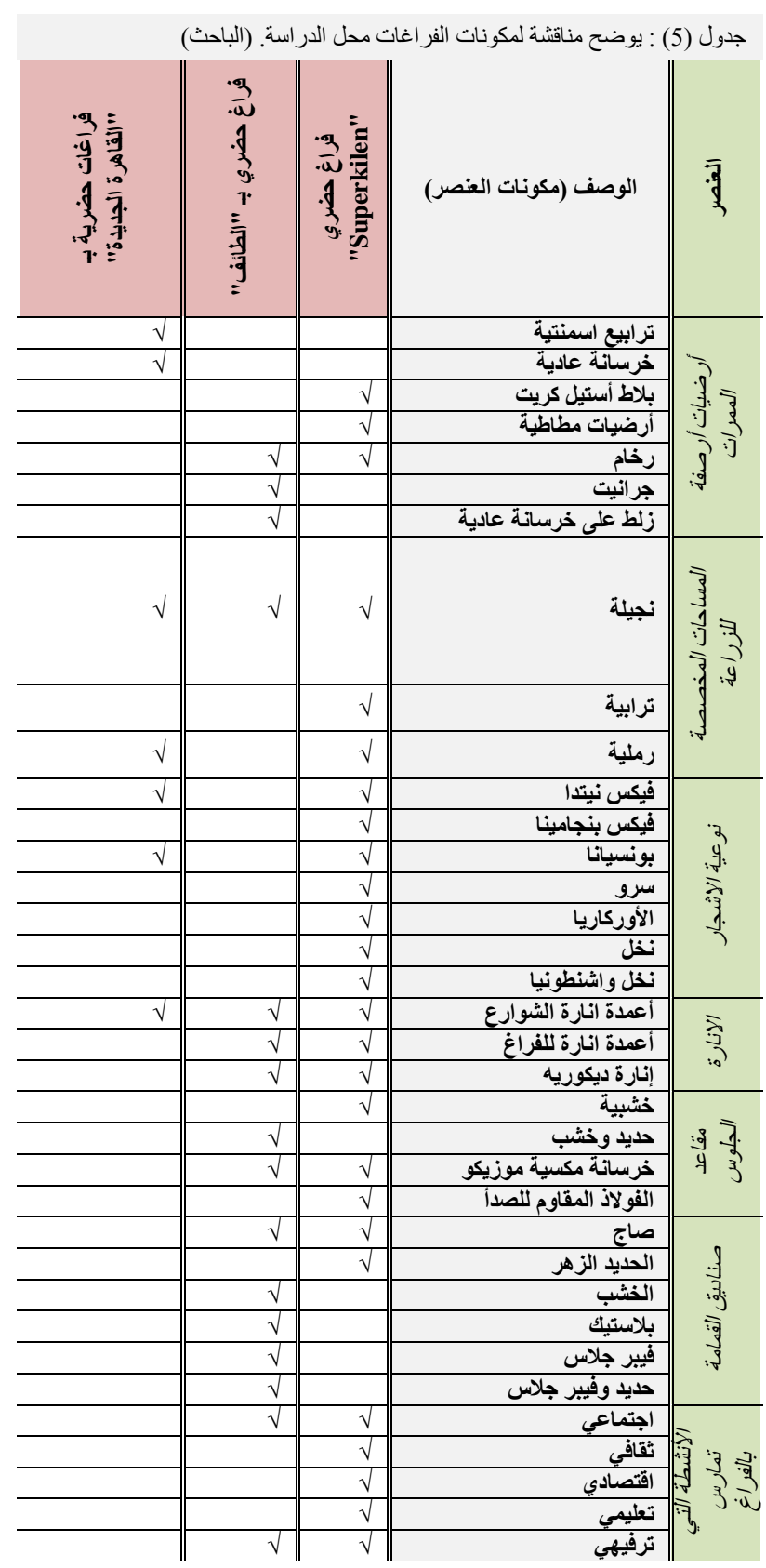

الفراغ الحضري "Superkilen" : يتوفر به جميع العناصر التي تعمل علي

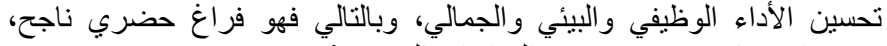
ويجب الاستفادة منه عند تصميم الفر اغات الحفئ الحضرية.

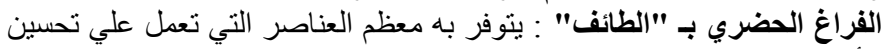

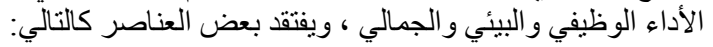

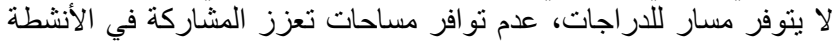

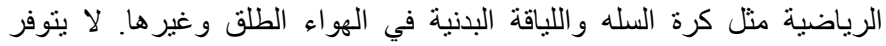
مساحات للعروض الترفيهية و الاستعر اضات ولئ 


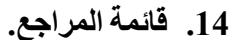

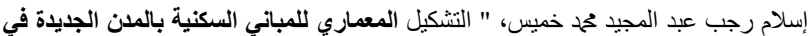

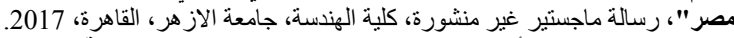

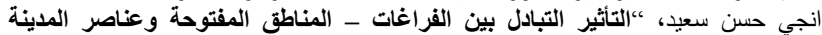

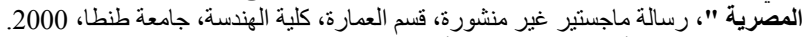

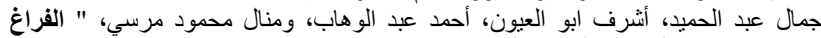

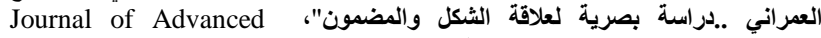
(Engineering Trends (JAET) جورج قتصلية، " الكفاءة الوظيفية والاجتماعية للفر اغات العمر انية العامة في مدينة اللاذقية"،

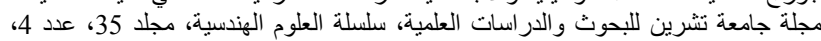
2013

خلف حسين علي الدليمي، "تخطيط المدن: نظرياتـ أساليبـ معايير - تقتيات"، الطبعة الأولي،

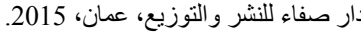

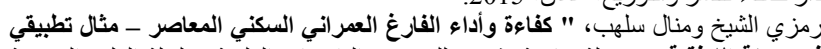

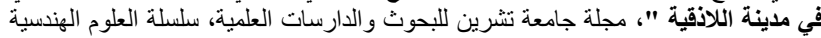

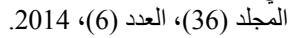

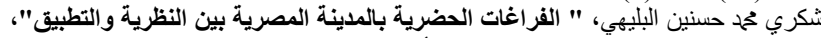

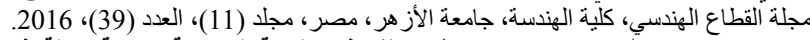

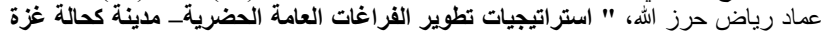

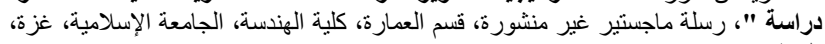
فلسطبن ، 2014.

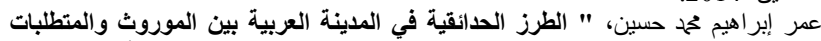

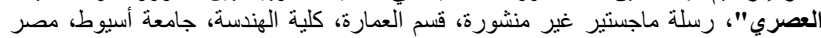
.2011،

[10] فراس نظمي مروح دويكات، "الفراغات العامة الحضرية وبصريا في مدينة نابلس وتطويرها

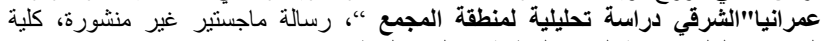

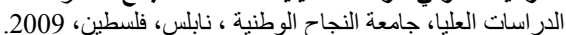

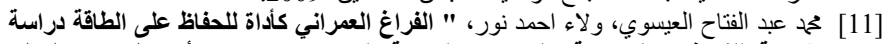

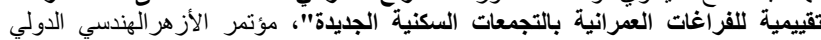

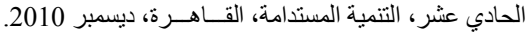

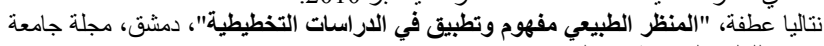

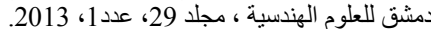

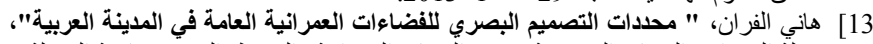

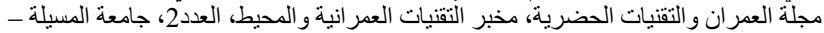
الجز ائر، العران 2010.

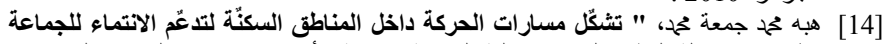

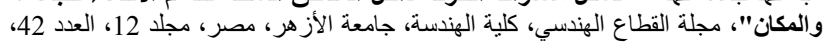
2017

[15] هند فؤاد جميل ياسين، " دور عناصر تنسيق الموقع في إثراء القيم الجمالية والوظيفية

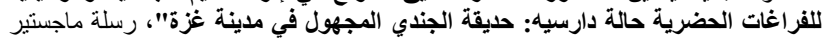

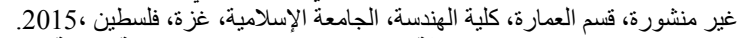

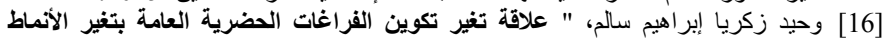

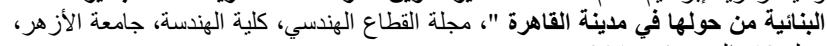

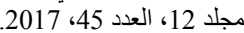

[17] وسام أبو الحجاج عبد الحكيم مهنا، " صياتة وإعادة إستخدام الفراغات العمرانية التراثية"،

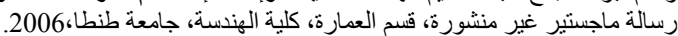

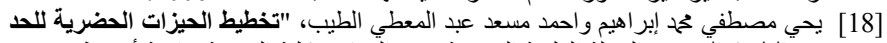

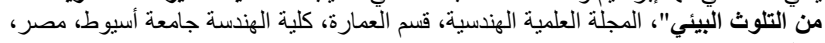

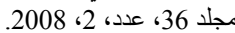

[19] وزارة الثؤون البلدية والقروية، " تقرير حالة ازدهار المدن- الطائف"، الرياض، الملكة

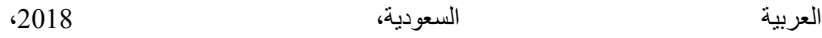
https://unhabitat.org/sites/default/files/2020/04/tqryr_halt_azdhar_almdn _-_altayf_2019.pdf

[20] Jan Gehl, " Life Between Buildings, Using Public Spaces ", Island Press, Washington, London, DC, $6^{\text {th }}$ edition, January 17, 2011.

[21] Johan Simonds, "Landscape Architecture". $5^{\text {th }}$ Edition Mc Graw-Hill, U.S.A, 27 February 2013.

[22] Kevin Lynch, "Site Planning”. The MIT Press, Cambridge, Massachusetts and London, Third Edition, 1984.

[23] Matthew Carmona, Tim Heath, Taner Oc and Steve Tiesdell, "Public Spaces - Urban Spaces: The Dimensions of Urban Design", $2^{\text {nd }}$ Edition, Architectural Press, Great Britain, 2010. 408 pp.

[24] Muhammad Yunus Fekry Amer, " Fine Values for Urban

Coordination in Spaces of New Communities of Economic Housing", (October 18, 2017). ARChive, Vol. 1, No. 1, 2017.

[25] Project for Public Spaces Inc, " Placemaking and the Future of Cities" , Produce under the auspices of the UN-HABITAT sustainable Urban Development Network (SUD-Net) with funding from the United National federal Credit Union, draft, Fall 2012,

[26] Roberto Brambilla, \& Giani Longon, "For Pedestrians Only: Planning Design and Management of Traffic Free Zones ", Whitney Library of Design, New York, 1977

[27] Samar Hamameh \& Gökçen Caymaz, "Evaluation of Aesthetic, Functional, and Environmental Effects on the Design of Urban
11. الخلاصة والنتائج.

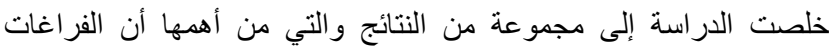

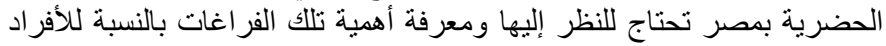

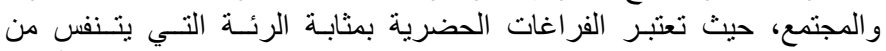

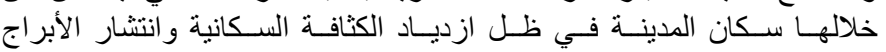

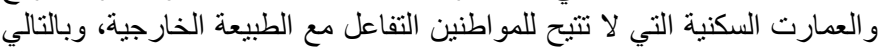

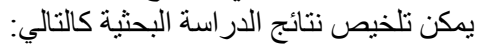

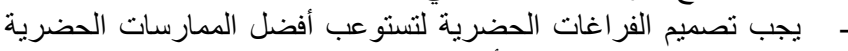

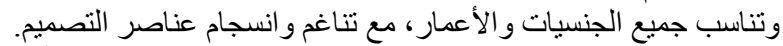

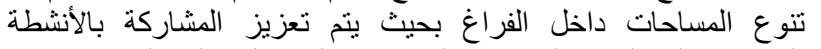

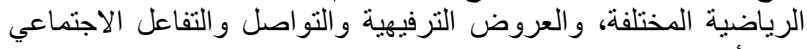

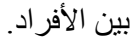

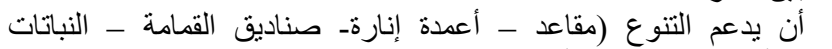

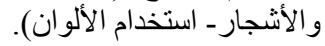

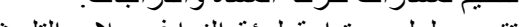

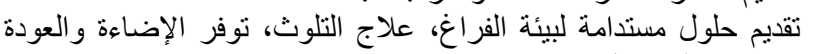

لاستخدام المواد الطبيعية.

الاهتمام بالعناصر التي تسهح وتعمل علي تلئي تحسين الأداء الجمالي كالمقياس

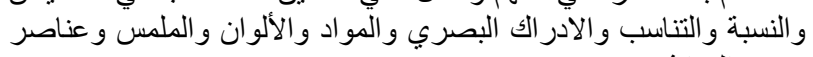
تتسيق الفراغ.

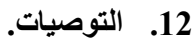

ينبغي على المخططين والمصممين عند تخطيط المدن الاهتمام بالفراغات

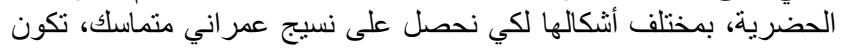

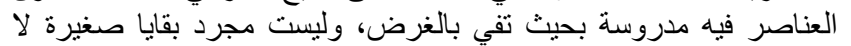

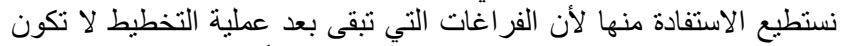

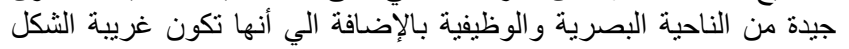
ومكلفة في الصبيانة.

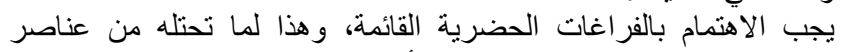

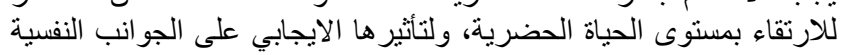

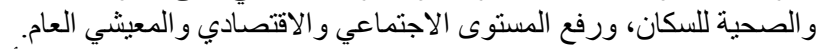

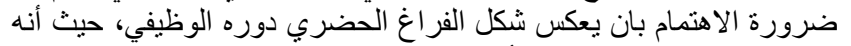

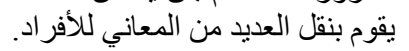

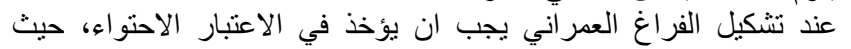

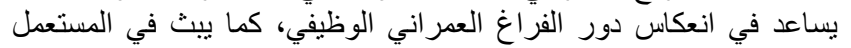
العديد من الاحاسيس و المشاعر المانس المختلفة. نشر الوعي لدي فئات المجتمع بالا هتمام بالفر اغلفة المات الحضرية.

\section{Authors Contribution .13}

We encourage authors to submit an author statement outlining their individual contributions to the paper using the relevant roles:

\begin{tabular}{|c|c|c|}
\hline & $\begin{array}{c}\text { first } \\
\text { researcher }\end{array}$ & $\begin{array}{l}\text { Second } \\
\text { researcher }\end{array}$ \\
\hline 1- Conception or design of the work & \multirow{8}{*}{$50 \%$} & \multirow{8}{*}{$50 \%$} \\
\hline 2- $\quad$ Data collection and tools & & \\
\hline 3- Data analysis and interpretation & & \\
\hline 4- $\quad$ Methodology & & \\
\hline 5- $\quad$ Resources & & \\
\hline 6- Drafting the article & & \\
\hline 7- Critical revision of the article. & & \\
\hline $\begin{array}{l}\text { 8- Final approval of the version to } \\
\text { be published }\end{array}$ & & \\
\hline
\end{tabular}

The corresponding author is responsible for ensuring that the descriptions are accurate and agreed by all authors. 
Title in Arabic:

دراسة تحليلية لانعكاس تصميم وتنسيق الفراغات الحضرية لتحسين أداءها

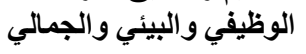

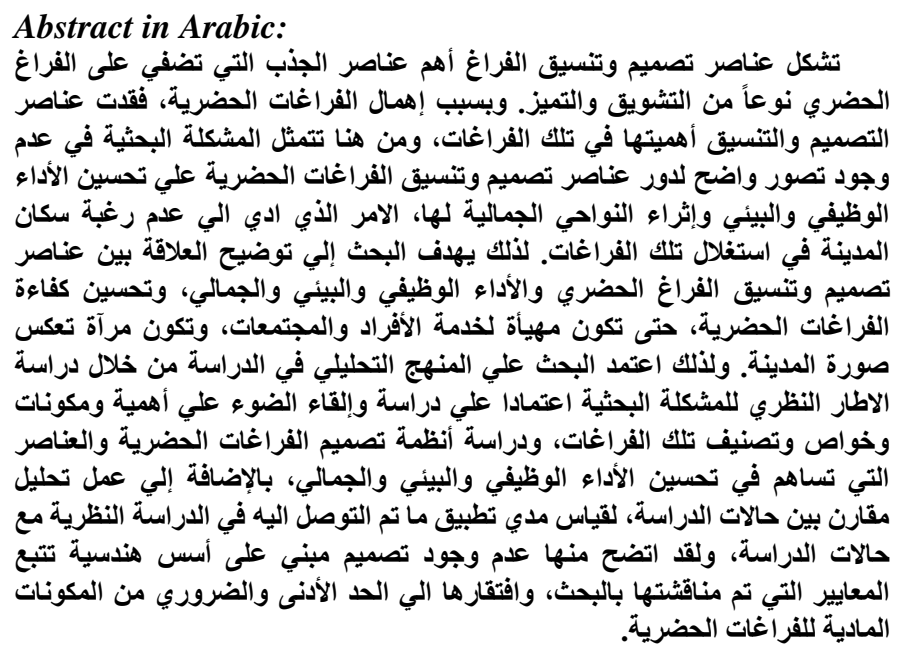

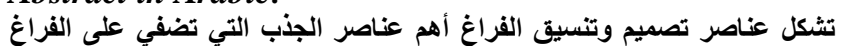

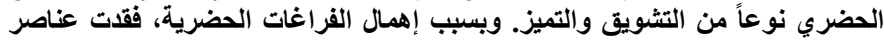

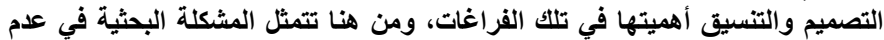

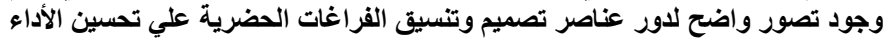

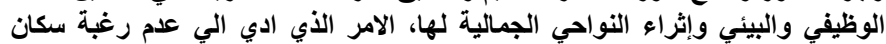

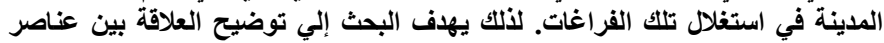

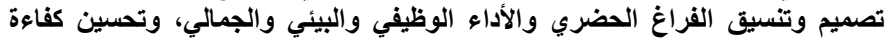

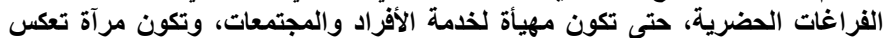

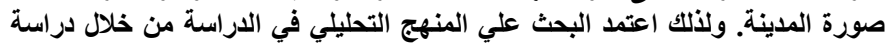

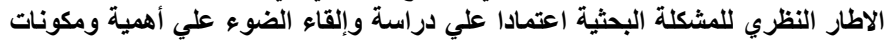

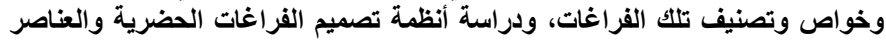

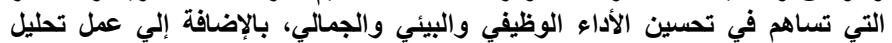

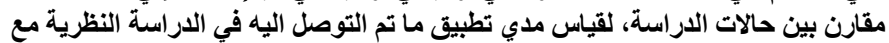

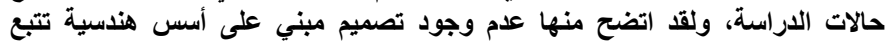

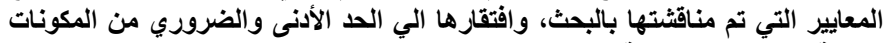
المادية للفر اغات الحضرية.

Open Spaces: A Case Study of İstanbul Şişhane Park, Turkey", Journal of Contemporary Urban Affairs, vol 4, n.2, 2020.

[28] Siavash Jalaladdini and Derya Oktay, " Urban Public Spaces and Vitality: A Socio-Spatial Analysis in the Streets of Cypriot Towns", ELSEVIER, SciVerse Science Direct, Social and Behavioral Sciences 35 (2012) $664-674$.

[29] Yoshinobu Ashihar ، "Exterior Design in Architecture" ،Van Nostrand Reinhold. New York. 1981.

[30] https://www.archdaily.com/948304 (November 2020)

[31] https://www.archdaily.com/950144 (November 2020)

[32] https://blogs.iadb.org/ciudades-sostenibles/en/public-space-for-all, November 2020.

[33] https://www.dezeen.com/2012/10/24/superkilen-park-by-big-topotek1and-superflex, November 2020.

[34] http://www.twentytwo-group.org/documents (February 2021)

[35] https://www.webbaviation.co.uk/aerial/picture.php?/30430 (February 2021)

[36] http://mmmmmsssmmm.blogspot.com/2017/03/blog-post.html (February 2021)

[37] http://kenanaonline.com/users/gardening/posts/133032?re=291403 (February 2021)

[38] https://www.elbalad.news/3831669 (February 2021). 